NPS ARCHIVE

1967

WELCH, R.

A STUDY OF THE STRATIFICATION OF PHYTOPLANKTON AT SELECTED LOCATIONS

IN MONTEREY BAY, CALIFORNIA

ROBERT HORTON WELCH 
LIEKARY

MAVAL POSTGRADUATE SCHDOS

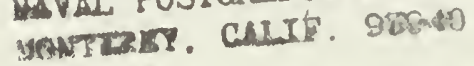


This document has been approved for public
release and sa.le; its distribution is unlint? 

$m 2$ ? 



\section{A STUDY OF THE STRATIFICATION OF PHYTOPLANKTON \\ AT SELECTED LOCATIONS IN MONTEREY BAY, CALIFORNIA}

by

Robert Horton Welch

Lieutenant, United States Navy

B.S., East Temassee State University, 1960

Submitted in partial fulfillment of the requirements for the degree of

MASTER OF SCIENCE IN OCEANOGRAPHY

from the

NAVAL POSTGRADUATE SCHOOL

June 1967 


\section{ABSTRACT}

Relationships between genera of phytoplankton present and the parameters of oceanographic reglme and nutrient supply have been given. The research was made at three selected off-shore stations in Monterey Bay, California. Sampling and analysis procedures are described. Results of nutrient anafsisido lude reactive phosphate and silicate. A temperature and salinity profile is described for each station. Phytoplankton analysis lists five genera of dinoflagellates and sixteen genera of diatoms. The research extended for a $s 1 x$ month period beginning in November, 1966, and was concluded in April, 1967. 


\section{TABLE OF CONTENTS}

Page No.

List of Tables 5

List of Figures 7

Acknowledgement 8

Introduction 9

Procedure 10

Oceanographic Pattern 15

Temperature, Salinity, and Climatic Analysis 18

Nutrients 28

Phosphorus 28

Silicon 40

Phytoplankton 45

Sampling Procedure 45

Generic Analysis 47

Conclusions 64

Bibliography 67

Distribution List 68 



\section{LIST OF TABLES}

Page no.

Table I Synoptic data for each station. 

Figure 1 Chart of Monterey Bay 11

Figure 2 Temperature and Salinity, Station $1 \quad 19$

Figure $3 \quad$ Temperature and Salinity, Station 2

Figure $4 \quad$ Temperature and Salinity, Station 3

Figure $5 \quad$ Bathythermographs, Station 1

Figure $6 \quad$ Bathythermographs, Station $2 \quad 24$

Figure 7a Bathythermographs, Station $3 \quad 25$

Figure 7b Bathythermographs, Station $3 \quad 26$

Figure $8 \quad$ Phosphate and Silicate, Station $1 \quad 30$

Figure $9 \quad$ Phosphate and Silicate, Station 2

Figure $10 \quad$ Phosphate and Silicate, Station $3 \quad 32$

Figure 11 Volume Phytoplankton ml/liter, Station 1

Figure 12 Volume Phytoplankton ml/1iter, Station 2

Figure 13 Volume Phytoplankton ml/liter, Station 3

Figure 14a Percent of total Phytoplankton of each Genus, Station 1

Figure 14b Percent of total Phytoplankton of each Genus, Station 1

Figure 15a Percent of total Phytoplankton of each Genus, Station 2

Figure 15b Percent of total Phytoplankton of each Genus, Station 2

Figure 16a Percent of total Phytoplankton of each Genus, Station 3

Figure 16b Percent of total Phytoplankton of each Genus, Station 3 


\section{ACKNOWLEDGEMENT}

Appreciation is given to the Chemistry Department for the ure of their equipment during nutrient analyses, and especially to Professor Charles Rowell for his time and help. I wish to thank my wife for her help both scientifically and secretarial. 


\section{INTRODUCTION}

While it is often difficult to accumulate sufficient raw data to justify conclusions on an oceanographic topic, the present work represents an effort to extend the knowledge of one small area of the sea so that hypotheses may be extrapolated for the broad reaches of the sea. In searching for a research topic, the accumulation of meaningful data was a prime goal rather than the quest for a startling new idea or conclusion. The topic search lead to a paper published in 1961 on the marine climate and phytoplankton of Monterey Bay by Drs. R. L. Bolin and D. P. Abbott of Hopkins Marine Station, Pacific Grove, California (Bolin and Abbott, 1961). Using this paper as a guide line, it was decided that meaningful information to supplement their data could be obtained by concentrating the research area and by varying the sampling procedure somewhat.

The sampling program was begun in November, 1966, early enough in the academic year to be able to collect data for a $81 x$ month period. Weekly samplings were attempted thereafter until April, 1967. 


\section{PROCEDURE}

Starting on November 9, 1966, three of the 8 ix original

'Hopkins' stations were occupled on a weekly basis for a period of six months. Rather than attempt a broad cross section of the Bay, as Bolin and Abbott did, the study centered on the first three stations located nearest the Monterey Marina. Flgure 1 shows the position of the stations. Station 1 is next to buoy number 4, Station 2 is in approximately 53 fathoms of water, and Station 3 is on the edge of the Monterey Canyon. The stations were chosen because of both the nearness to the Marina and the broad range of depths that are encountered. With each cruise the stations were occupied using the most precise navigation avallable. This usually consisted of radar ranges and fathometer reading8. Deviation from the station during the sampling was minimal and usually was restricted to \pm 200 yards.

On station a bathythermograph cast was made to the maximum allowable jimits, that is, either to near-bottom depth or to the operational limit of the BT. At the same time a bucket sea surface temperature was read, a dry bulb alr temperature was taken, and visual observations were made of wind speed and direction, sea, swell direction and helght, barometer reading, descriptive sunlight, and percent cloud cover (Table 1). A Secchi disc was lowered to obtain a measure of the transparency of the water.

Since the Hopkins project had included only a vertical haul from 15 meters, the depth for the present research was restricted to this layer. Before the study had commenced it was decided tinat stratified samples at 7.5 and 15 meters within the layer would be 


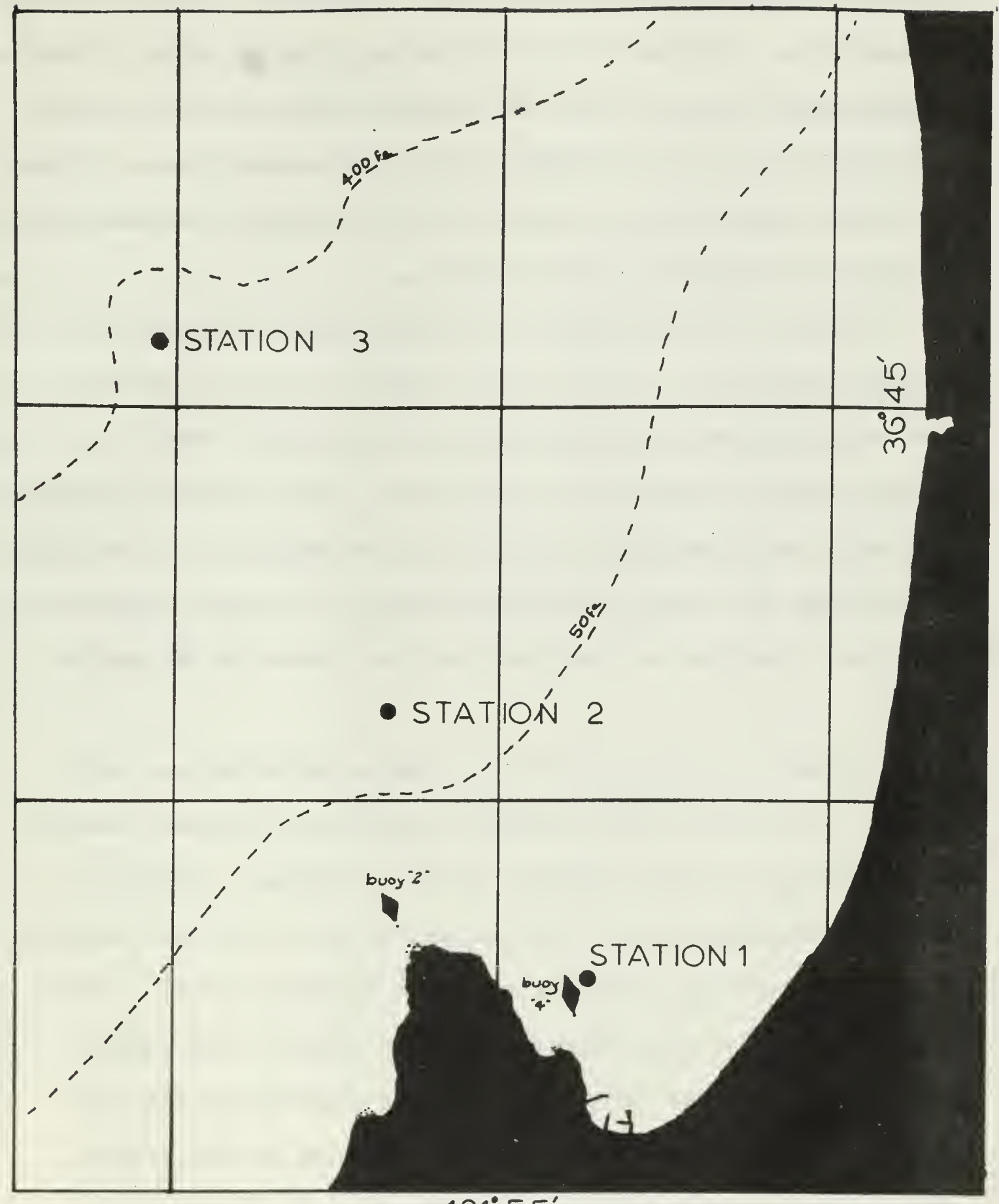

$121^{\circ} 55^{\prime}$

FIGURE 1. Chart of Monterey Bay showing the location of the three stations. 
about the maximum sampling that analysis time would allow. In order to Insure that the sample had come from the selected depths, a ClarkeBumpus sampler was used. With this sampler one is able to lower the collecting net to the preselected depth, open a plate valve, sample the level, close the net and return it to the surface uncontaminated by water and organisms of other levels.

To insure that the smallest possible identifiable planktonic plant was captured, a size 20 net and bucket was used. Complete flushing of the net accompanied every haul to prevent depth to depth or station to station contamination. Since the Clarke-Bumpus sampler is outfitted with an impeller driven counter it was possible to determine the volume of sea water sampled. To make a representative haul, sampling was continued for five minutes at the sample depth.

A plankton sample was made at a depth of seven and one half meters. At the end of the sampling, a Nansen cast was made placing the bottles at 15 and 7.5 meters, and at the surface. Protected reversing thermometers were used on each bottle to obtain a precise temperature profile of the station at the sampling depths. After the Nansen bottles were tripped and hauled aboard, water samples were extracted in the following manner: a glass bottle was used to receive a salinity sample, and two four ounce plastic bottles were used to recelve phosphate and silicate samples (these were immediately injected with about $0.5 \mathrm{ml}$ of chloroform to retard bacterial growth, and then were placed in an ice bath).

The second plankton sample was then taken. By reversing the course of the boat, sampling was possible - neglecting drift - over 
the same general area as before but at the depth of 15 meters. Both plankton samples were placed in pint jars and preserved on station with $20 \mathrm{ml}$ of $40 \%$ formaldehyde.

Cruise time was about five hours, depending upon weather conditions. Each station was occupied at about the same general time during each cruise. There are two time groups, however, the first includes the first seven cruises November through December occuring from 0800 through 1000 local time, the second group includes the remaining cruises with the time interval on station from 1000 through 1300 local time. Stations were generally occupied in the order from seaward to shore. However, climatic conditions often required a reversal of this pattern. Cruise 非 was incomplete due to foul weather and Cruise 非 has a plankton sample missing at Station 1 due to broken gear. 
Table I. Synoptic data for each station. Water-Transparency (Tr) given in feet; sunlight (S1) given as bright (b), hazy (h), or overcast $(0)$; sea condition given as calm (c), moderate (m), or rough $(r)$; and time of station.

Cruise

Station 1

Station 2

Station 3

Tr S1 Se Time

Tr S1 Se Time

Tr S1 Se Time

1

$\begin{array}{llll}53 & \text { b } & \text { s } & 0720\end{array}$

$\begin{array}{llll}49 & 0 & \mathrm{~m} & 0825\end{array}$

45 ○ 0935

2

- b 8105

- b s 0951

- b m 0825

3

40 b s 1046

$\begin{array}{llll}55 & \text { b } & 8 & 0945\end{array}$

$69 \mathrm{~h} \quad \mathrm{~s} \quad 0815$

4

55 h m 1035

60 h m 0935

$68 \mathrm{~h} \times 0825$

5

$\begin{array}{llll}14 & \text { h } & 8 & 1032\end{array}$

$\begin{array}{llll}17 & h & m & 0924\end{array}$

$61 \mathrm{~h} \times 0803$

6

21 h s 0703

20 h s 0815

$\begin{array}{lll}49 \text { h } & 8 & 0937\end{array}$

$\begin{array}{llll}39 & \text { b } & 8 & 1045\end{array}$

33 b m 0943

26 b m 0815

8

31 ○ \& 1350

$\begin{array}{llll}32 & \mathrm{~h} & \mathrm{~s} & 1225\end{array}$

50 h $8 \quad 1043$

9

50 h m 1312

54 b m 1155

48 b r 1032

10

60 b s 1355

$\begin{array}{llll}70 & \text { b } & \text { s } & 1208\end{array}$

82 b m 1045

11

43 b c 1340

$\begin{array}{llll}45 & \text { b } & 8 & 1235\end{array}$

51 b m 1105

12

19 b c 1305

12 b c 1200

$\begin{array}{llll}36 & b & 8 & 1035\end{array}$

13

$15 \circ \mathrm{m} 1345$

$\begin{array}{llll}13 & \text { b } & 8 & 1245\end{array}$

$\begin{array}{llll}21 & b & 8 & 1118\end{array}$

14

$18 \circ \mathrm{m} \quad 1000$

$23 \circ$ × 1101

$28 \circ \times 1211$

15

29 b s 1400

$37 \mathrm{~h} \quad \mathrm{~s} \quad 1211$

46 o c 1045

16

43 b m 1412

$\begin{array}{llll}39 & \text { b } & \text { s } & 1205\end{array}$

$63 \mathrm{~b}$ s 1050

17

43 h s 1400

37 ○ 1220

47 - m 1050

$$
23 \text { o s } 1255
$$

43 ○ 1140

37 ○ \& 1035

16 ○ 1405

$33 \circ \times 1300$

31 b m 1140

$$
20 \text { o c } 1320
$$

40 ○ c 1215

36 o c 1053

16 b m 1317

25 b m 1220

12 b r 1105 


\section{OCEANOGRAPHIC PATTERN}

The oceanographic pattern of Monterey Bay is definitely seasonal with three distinct periods occurring during the year. Beginning sometime in November a northerly flowing current develops along the California coast which is called the Davidson Current. Reinforced by winter-time southerly winds, the current develops a net on-shore transport due to the Coriolis effect. Surface water, therefore, piles up along the coast and is continually sinking to be replaced by the shoreward flowing surface waters. As the Davidson Current continues, unstable water layers develop due to the surface water substitution and mixing occurs with the abnormally cold, previously upwelled water. This situation causes a sharp drop in the temperature structure of the bay. This sharp drop in temperature marks the onset of the Davidson Current Period. Due to the mixing processes, the thermal structure becomes uniform. Since the period occurs during the normal winter rainfall season surface salinities drop to low values. The lowest temperature and salinity values do not occur within the period, however, since time is required for mixing. The temperature minimum usually occurs in April while the salinity minimum at sea occurs during March. Nutrient supply in the surface layers is increased due to the vertical mixing and turbulent action caused by the storm season and the current structure close to shore.

In late winter the wind shifts, causing a reversal of the Davidson Current. This occurrence is not as abrupt as the initiation of the northerly-flowing Davidson Current so that it is often difficult to pinpoint the exact time of the second and longest period - 
the Upwelling Period. By early spring the winds have shifted, coming from the northwest which reverses the surface current direction. Surface waters are moved seaward, causing a divergence zone near the surface. As cold, deeper water moves toward the surface, It follows the upwelling pattern which occurs all along the coastal region. It is over the Monterey Canyon that the effects of the upwelling are first noticed in the form of cold surface temperatures. By May, the initially uniform temperature structure has been altered from both below and above. At first, the upwelling causes the total column of water to cool so that minimum surface temperatures occur in Apri1. In May and June the surface water begins to warm due to seasonal heating; however the deeper layers continue to cool, producing a very sharp themocline gradient at about 150 feet of $60^{\circ} \mathrm{F} / 100^{\prime}$.

As the deeper waters are upwelled, nutrients are brought from the deeper regions of nutrient abundance toward the surface. It is in this early spring period that plankton populations increase and continue to do so until late summer where they die out due to the lack of nutrients after upwelling has diminished. Accompanying the upwelling, a more saline water is brought to the surface layer so that during the early part of the upwelling period the salinity curve shows corresponding changes. As mixing occurs and upwelling diminishes in late sumer, the salinity of the surface water begins to decrease.

During the months of September and October, winds become variable and a period of relative calm prevails. It is during this time that the cool, saline waters of the surface become colder and begin to sink. 
As the surface waters sink, offshore waters move in to replace the 1ayer. During this Oceanic Period the warmest water of the year occurs at the surface. The period is marked by clear blue oceanic water, and a relatively uniform cold water column.

The surface water shows a secondary salinity maximum as the low salinity mixed waters are replaced by higher salinity oceanic water. Characteristic plankton will be the open-water species that survive on minimal nutrient or food supply. 
TEMPERATURE, SALINITY, AND CLIMATIC ANALYSIS

All three oceanographic periods were encountered during the period described in the research project, however, the Upwelling Period observed shows a variation from the description outlined above.

The Oceanic Period was in progress when the first cruise was made on November 9. This period continued until early December when the first drop in temperatures was recorded at all three stations on December 4. The period was marked by warmer waters with intermediate salinity values. A very definite period of nutrient minimum was noticed. Silicates reached a value of less than 0.5 micro-gram atoms per liter ( $\mu \mathrm{gm}$ at/1iter) and phosphate values approached $0.1 \mu g m$ at/liter.

The Davidson Current Period appeared somewhat late, beginning in late November or early December. In Figures 2, 3, and 4 it is seen that the surface temperature begins the first sharp decline on December 7, but the 7.5 and 15 meter level decline 18 two weeks earlier, occuring on November 23. These Figures also show the salinity values which give their first decline at all depths on November 30. In Figures 2 and 3, the temperature minimum occurs at all depths on January 4 with a minimum of $10.7^{\circ} \mathrm{C}$ occurring at Station 1 at depths of 7.5 and 15 meters. However the minimum did not occur at Station 3 until two weeks later on January 18 (see Figure 4). This is probably because the longer water column requires a longer period to cool and because of the distance from shore. From the end of each minimum, the temperature became progressively warmer until early February. This warming occurred as an abrupt change in 


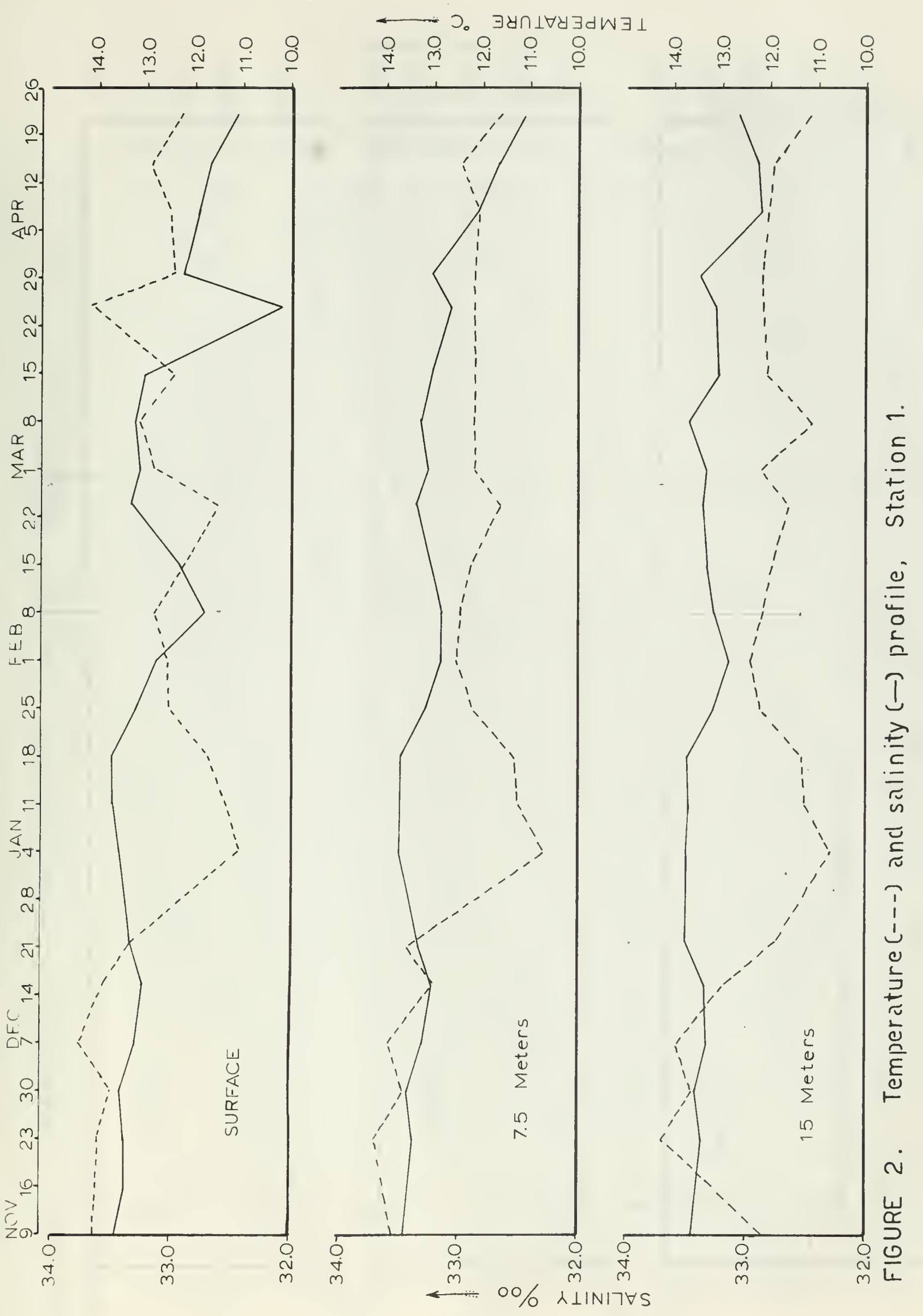




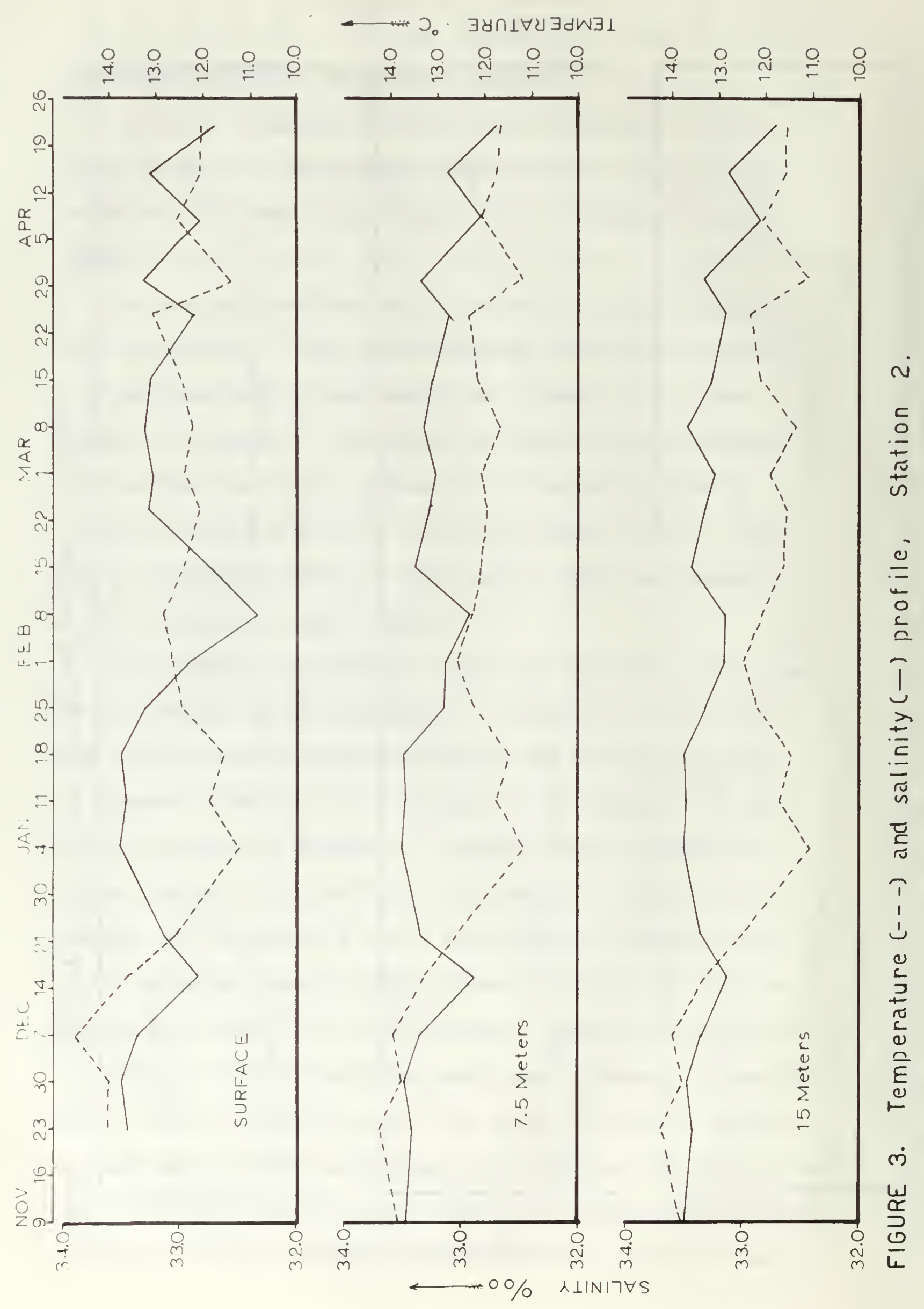




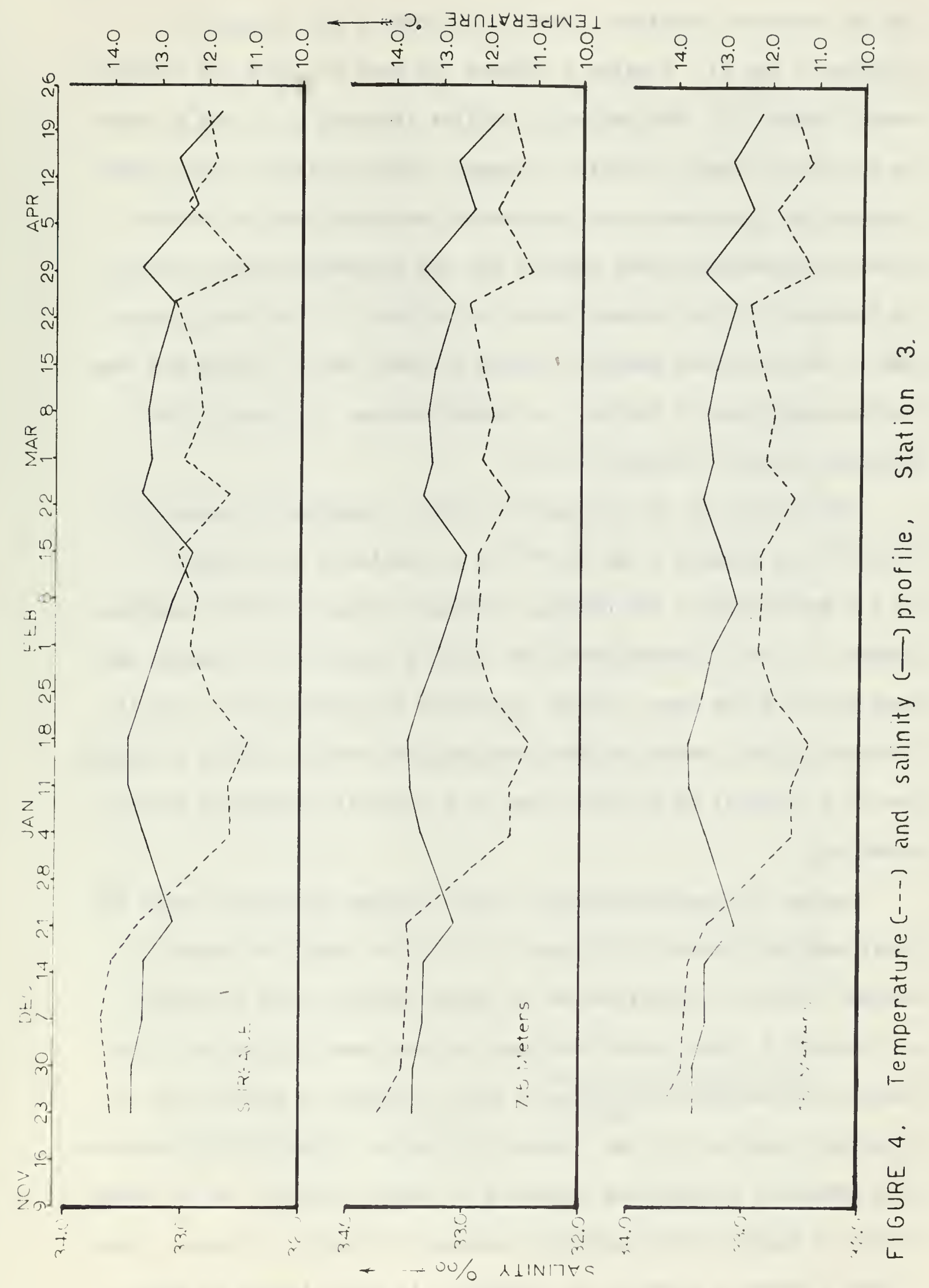


the BT traces at Stations 1 and 2 on January 4 and January 11

(Figures 5 and 6). Station 3 (Figure $7 a$ ) does not show the increase until January 25. The salinity profiles (Figures 2, 3, and 4) show an increase, after an initial decrease, which continues until about January 18. This continued increase of salinity profile, rather than the expected minimum profile for the Davidson Current Period, is explained by the unusual delay in the onset of the rainy season and by the turbulent vertical mixing to lower layers during the near uniform post-0ceanic Period. As rains occurred in January, the salinity started a downward trend.

The decline at the surface was abrupt, reaching a minimum of $32.72 \%$ at Station 1 and $32.34 \%$ at Station 2 on February 8. At 7.5 and 15 meters the decrease was more gradual at both stations; however, at the 15 meter level the minimum salinity was reached one week ahead of the upper layers, occurring on February 14. This is interpreted as a result of the diminished shoreward surface transport due to a reversal of the wind, and as a possible initiation date for upwe11ing.

During the Davidson Current Period, mixing is evident until the first week on February 4 (Figure $7 \mathrm{~b}$ ). On this date the trend of mixing downward is reversed and an upward mixing trend is evident on February 8, which marks the onset of the Upwelling Period. The temperature decrease beginning in early February is gradual, as is expected, being only a few tenths of a degree. The salinity increase that generally accompanies upwelling is large, however, on the order of six to eight tenths parts per thousand initially. Stations 1 and 2 show a definite matching of trends at all three layers as shown 


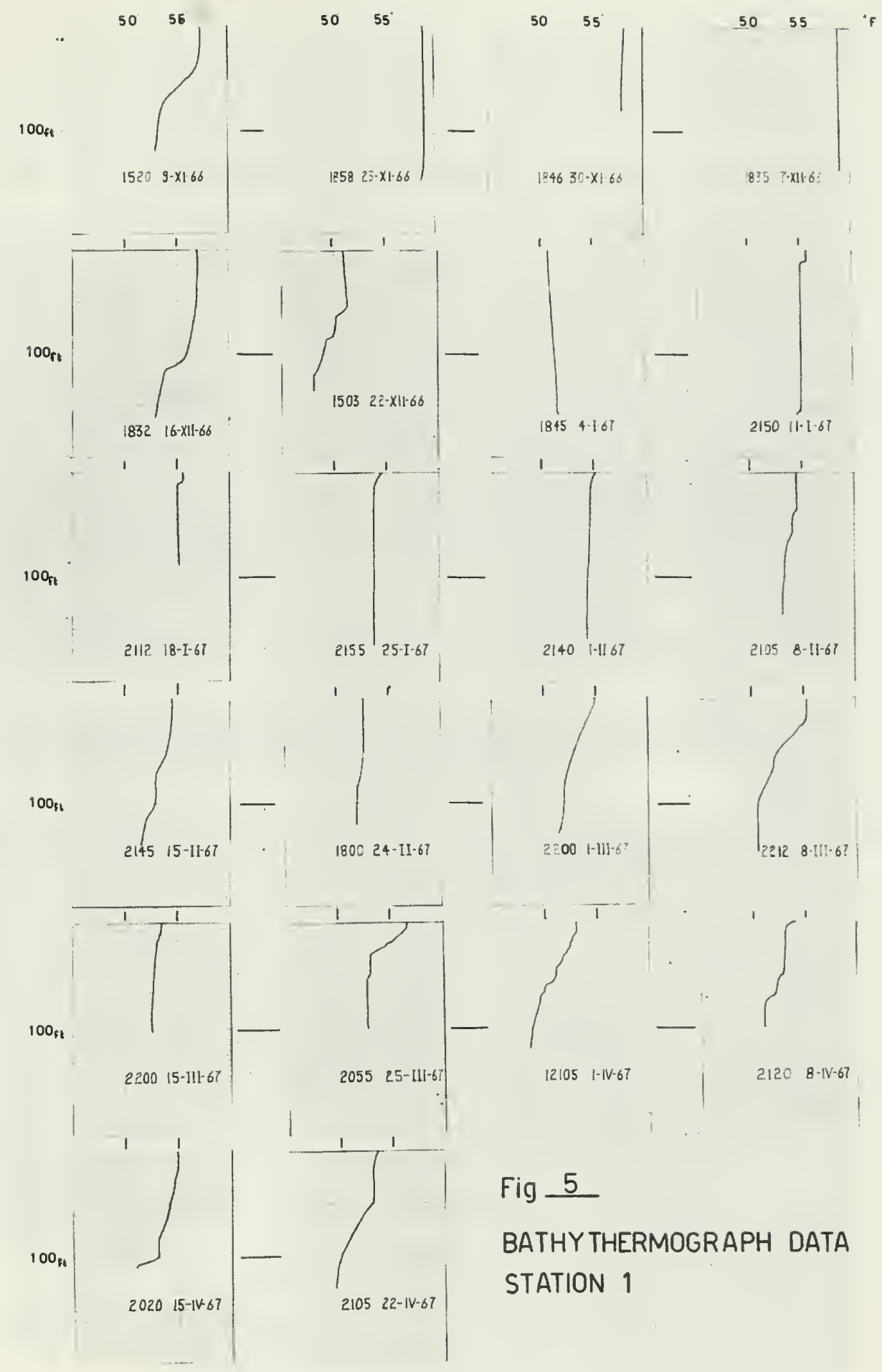




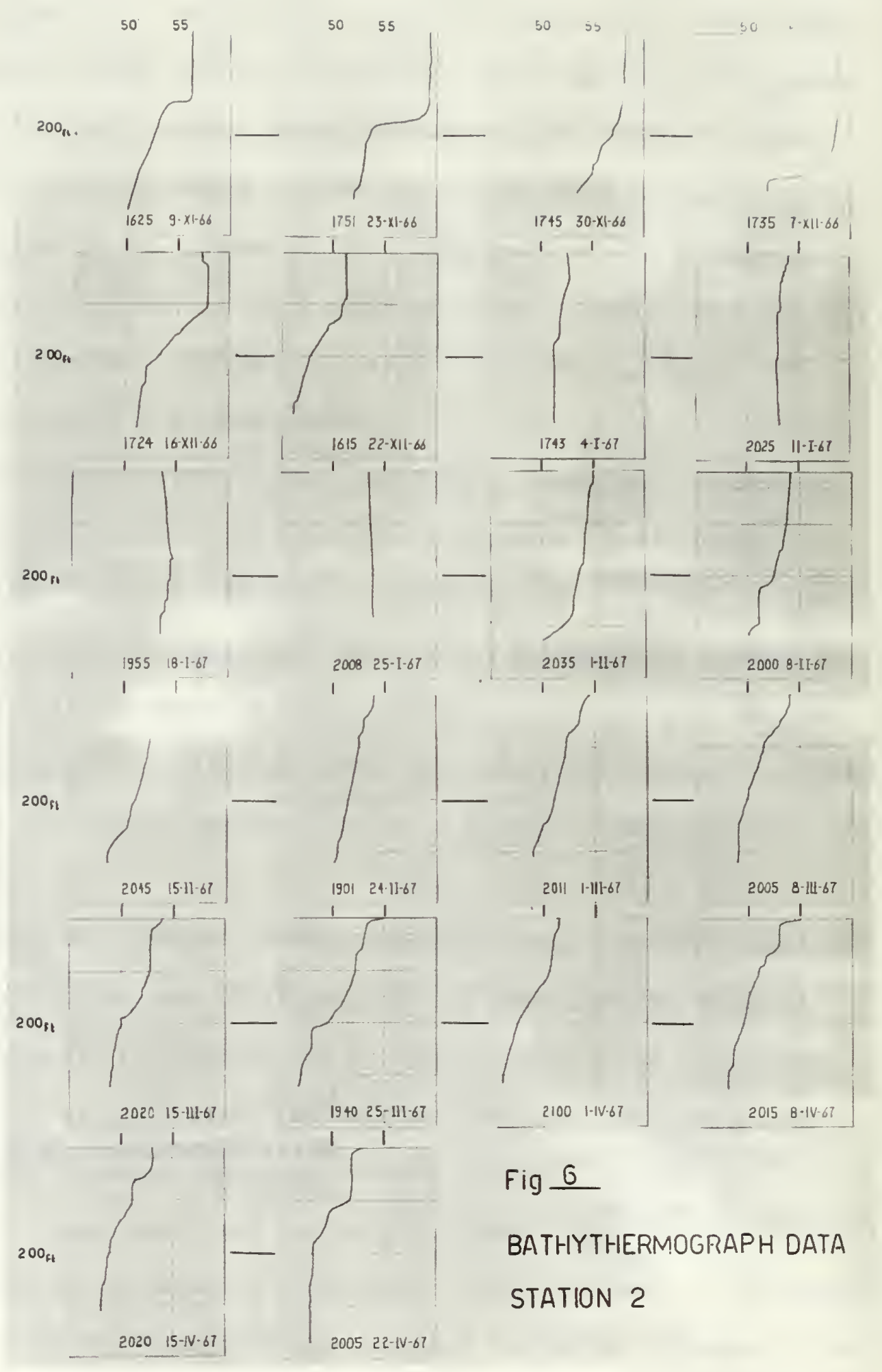




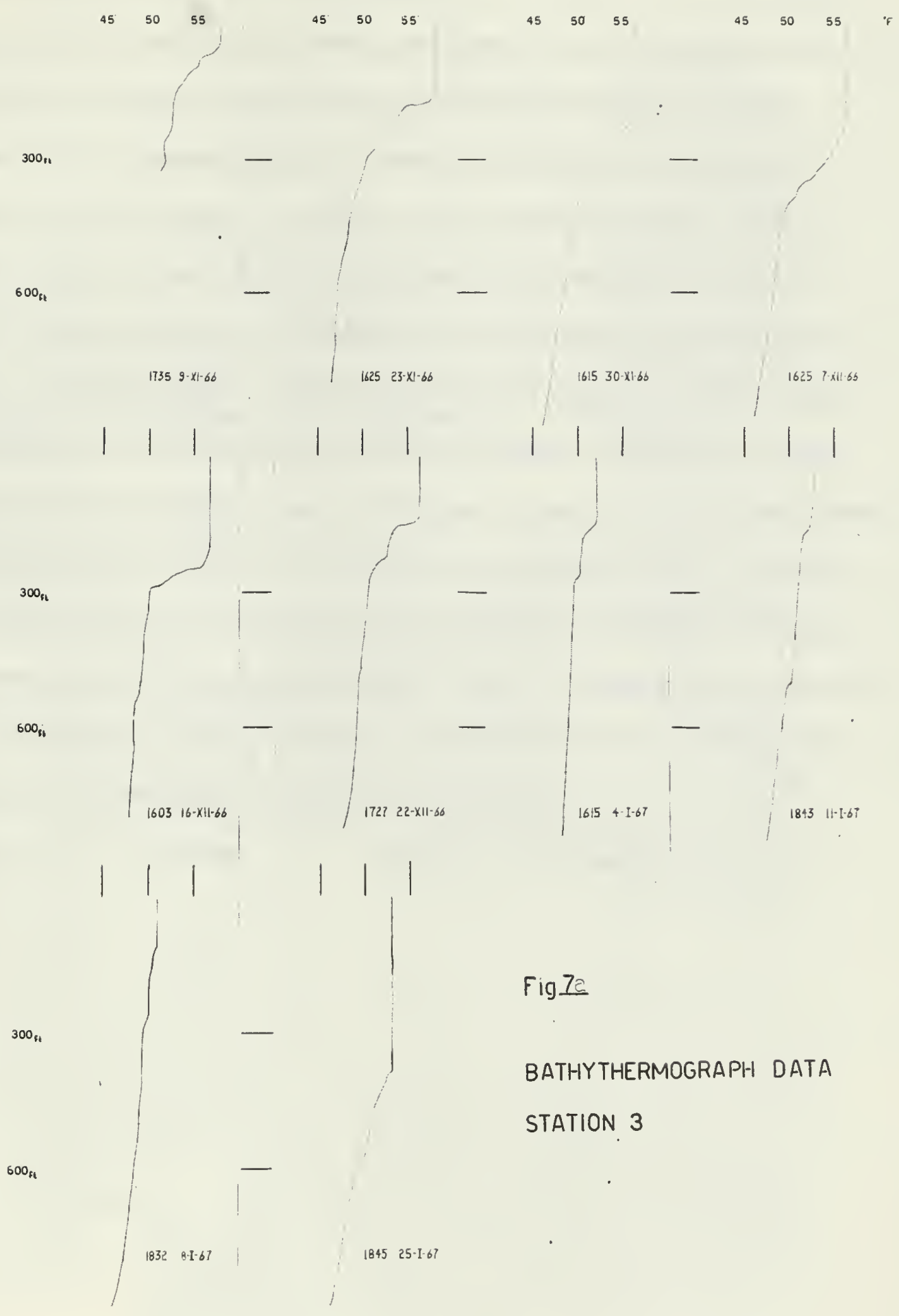




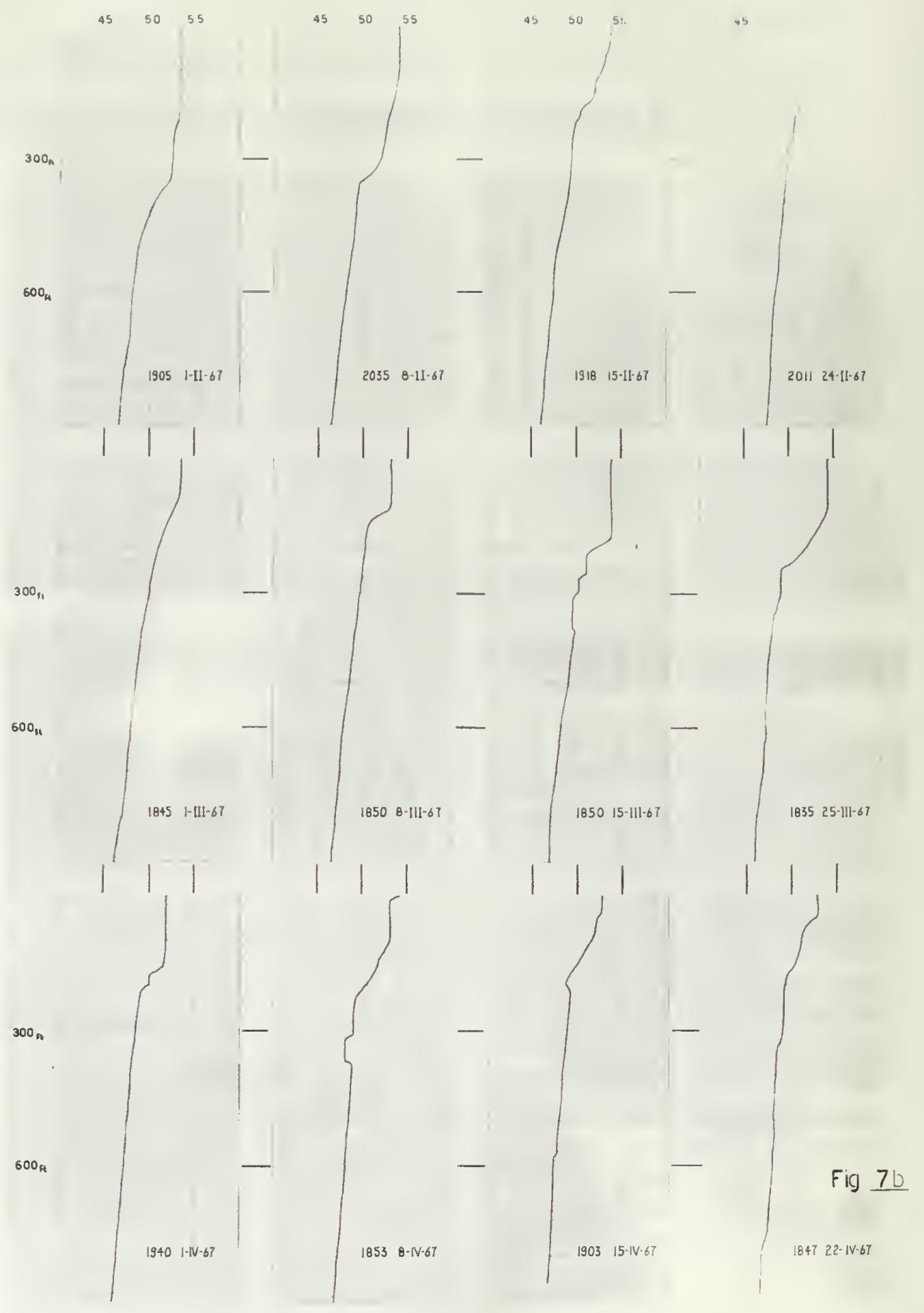


by Figures 2 and 3 . Station 3 responds to temperature and salinity patterns slower and much less markedly.

The normal salinity increase and temperature decrease that accompanles the Upwelling Perlod was altered radically by the presence of an unusually large amount of rainfall in mid-March through the end of April. Despite the warming influence of the rainfall, mean curves for all stations at all depths (F1gures 2, 3, and 4) show a gradual decrease in the temperature profile. The salinity profile varies from that expected beginning in March when the freshwater effects due to rainfall exceeds increased salinity efforts due to the still weak upwelling, giving a diminishing trace for salinity rather than the expected increasing profile. During April this imbalance moves the plot of Station 1, shown in Figure 2, downward toward an all semi-annual low. In Figure 3, the salinIty curve for April shows sporadic high and low values due to the occurrence of both upwelling and heavy rain. 
NUTRIENTS

Wimpenny (1966), Newel1 \& Newel1 (1963), Cupp (1943), and especially Raymount (1963) have stressed the importance of adequate nutrient supply for growth in their treatments of productivity of plankton. Other investigators (Bolin and Abbott, 1963) list an additional requirement of adequate solar energy supply. Within Monterey Bay the nutrient level is determined primarily by the regime that is in operation. The Oceanic Period brings depleted surface waters from the open sea. The Davidson Current produces a relatively moderate nutrient level due to the shoreward movement of the waters and vertical mixing. The Upwelling Period brings very rich supplies of nutrients to the surface layers from the great depths of the Monterey Canyon. In the particular time interval studied during this research, one would expect a rather low value for nutrients at first, a moderate increase during the Davidson Current Period, and then a greater increase at the beginning of upwelling. Due to the imitation of time required for analysis it was decided that phosphorus and silicon would be the only parameters used as an index to the nutrient structure of the bay. PHOSPHORUS

Since phosphate is essential for phytoplankton productivity, measurements of phosphate concentration in the bay can be directly associated with phytoplankton blooms. Samples were collected for each depth, at each station during every cruise. Sample removal has been discussed previously under the Procedure Section.

Samples were chilled in an ice bath until they were placed in a freezer about three hours later. Two or three samples were lost 
because of defective plastic bottles but those lost occurred so randomly that any curve for a station/depth was not materially affected. The analysis of the samples occurred anywhere from four to eight weeks after collection. The loss of phosphate during storage is considered minimal due to the fact that the samples were pickled and then frozen.

Analysis of the samples followed procedures outlined in an unpublished Naval Postgraduate School Chemical Oceanography Laboratory Guide and based on the molybdate reduction with stannous chloride as given in Strikland and Parsons (1965). A standard of potassium hydrogen phosphate was used each time an analyis group was made. Analysis accuracy is given as $\pm 0.025 \mathrm{mgm}$ at/1iter, with a minimal detection level of $0.03 \mu \mathrm{gm}$ at/liter for accurate results. Technique accuracy is considered good with only three possible erratic points occuring at Station 1 on November 9 at 15 meters, at Station 2 on November 30 at the surface, and at Station 2 on December 25 at 15 meters. Due to the large number of samples taken that followed the expected and consistant patterns, these three unusual points cannot be discounted, but on the other hand they can not be explained. The discussion of the results will not include these three points as significant deviations.

The selection of the stannous reduction of the phosphomolybdate complex to a group of blue compounds was due to several reasons. Primarily, the technique was familar, the equipment was available, and the time required for analysis was shorter. Also the technique is universally used so that similar analysis may be made with equal technique precision. Lastly, the technique gave the necessary 


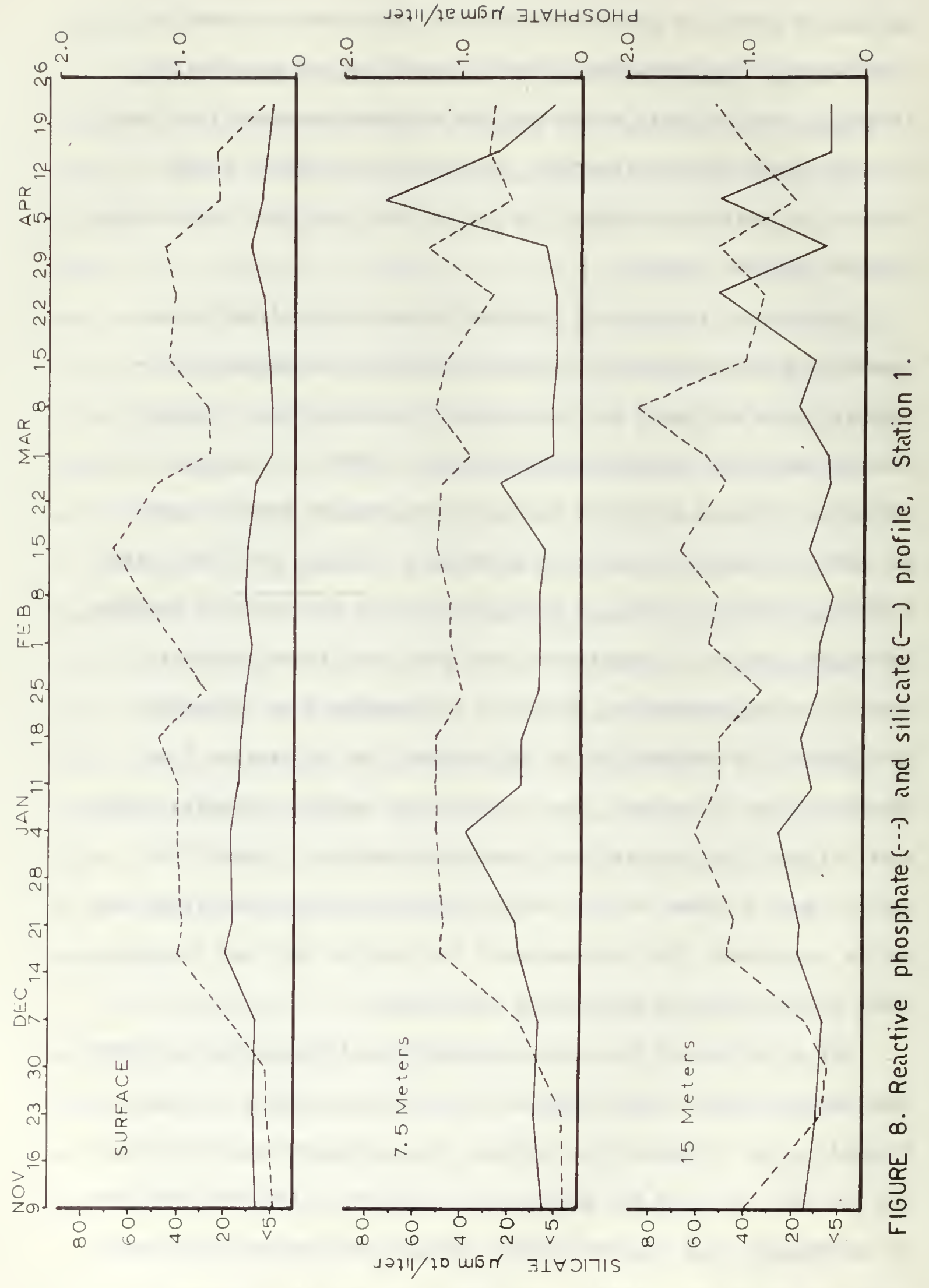




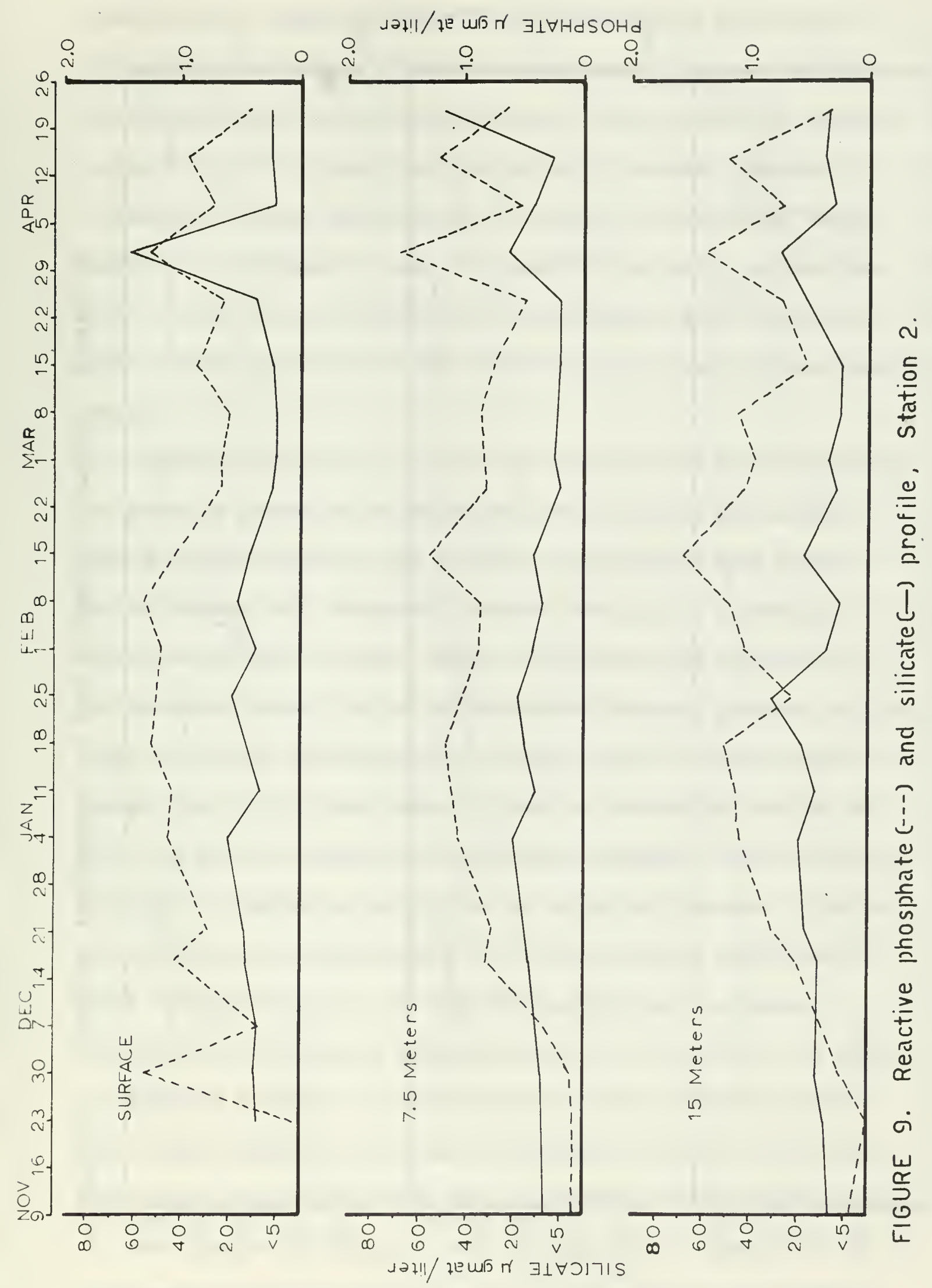




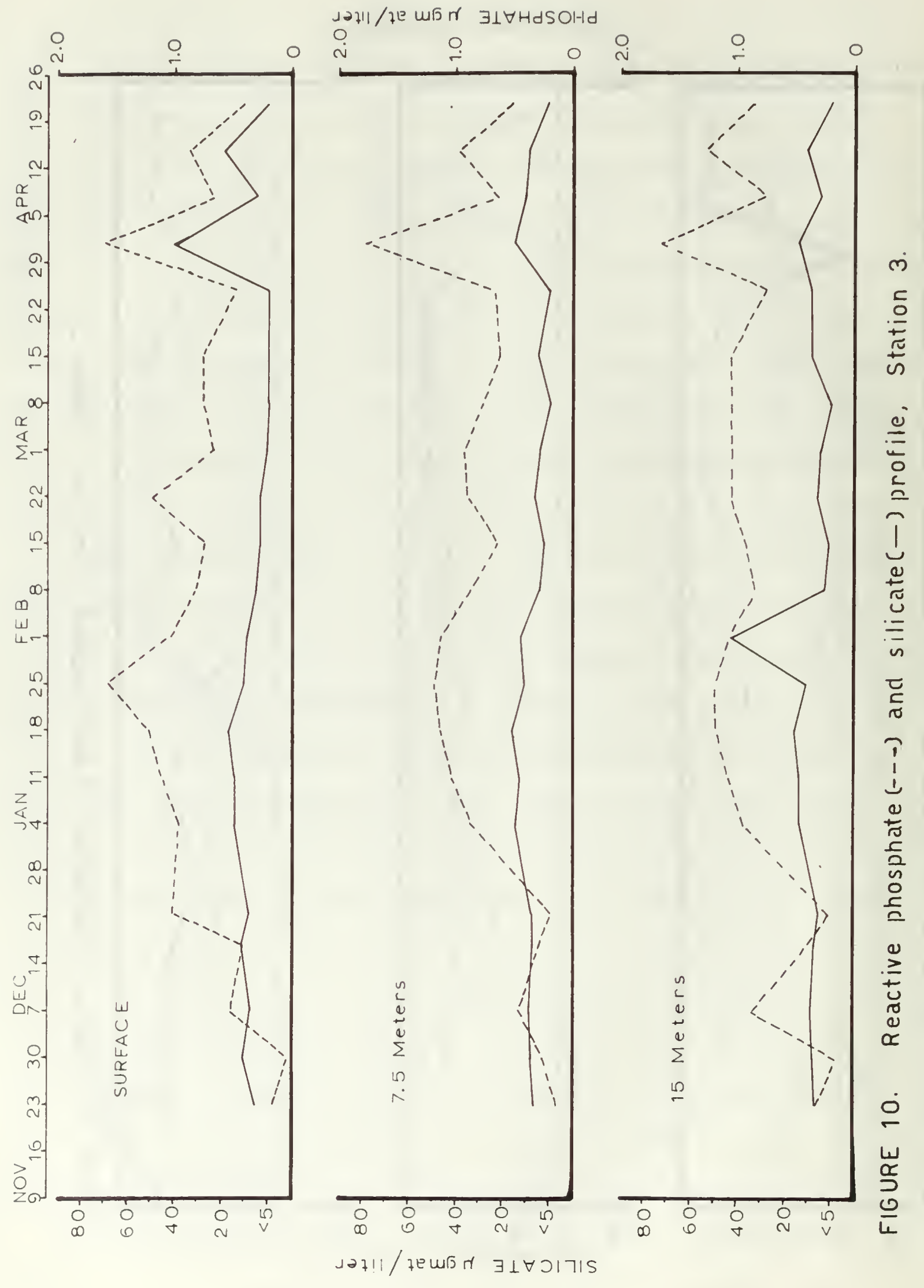


accuracy for a meaningful study. Extinction values were read at $625 \mathrm{~m} \mu$ from the Beckman DU and DK $1 \mathrm{~A}$ spectrophotometers. The DU Spectrophotometer requires manual control, while the DK IA Spectrophotometer gives automatic printed values of percent transmission. Transmission values were plotted on $10 \mathrm{~g}$ paper to allow for direct reading of absorbance values. Transmission extinction values were more valuable than absorption since logrithmetic plots displayed more accurate gradients of the standard curve in the low absorbance range.

Shown in Figures 8,9 , and 10 are plots of the resulting curves for reactive phosphate and silicate given per depth per station. From this gross analysis one sees that the nutrient poor Oceanic Period extends well throughout November with values approaching less than $0.2 \mathrm{\mu gm}$ at/1iter. Early in December with the onset of the Davidson Current, values of phosphates increase somewhat and then level off during late December and early January. This increase is brouglt about by the near shore position of the station and by the fact that on shore surface water carrying December runoff and river outfall are brought out in the Bay by subsurface movement. Another source for this nutrient supply is the here-to-fore nonvertically mixed subsurface waters. As the Davidson Current progresses, increased vertical mixing brings nutrients to the surface. A gradual decrease occurs at all stations until early February, when a small sharp increase occurs due to upwelling, and then a reduction again occurs until late March when a second upwelling maximum occurs. The pattern of Station 1 given in Figure 8 is about what one would expect for the research period. The Oceanic Period through 
November 30 is characterized by nutrient depleted water, the slight gradual increase of the phosphate value during December, and the subsequent lowering of concentration in January. Wheit Figure 11 is compared with Figure 8, it is evident that the small bloom of phytoplankton occurring on January 18 at 7.5 meters is responsible for the phosphate loss also occurring on that date. Contrary to the temperature-salinity curves presented earlier, there is no large increase in the phosphate concentration in early February to signal the onset of the Upwelling Period. The increases are seen only at the surface on January 18 and at 15 meters on March 1. However, when one considers that upwelling was gradual in starting and not able to reach to the shoreward stations at this early date, the curve is representative as indicated in Figure 11. Very large phytoplankton blooms occurred on March 8 and April 1. It is shown by the plotted curves that nutrients brought to the area were minimal due to the large amount of utilization during the blooms.

The profiles at Station 2 are generally the same as Station 1. When Figure 9 is placed near Figure 8, one can observe that the general low nutrient Oceanic and moderate nutrient Davidson Current Periods are similar. Here too, on January 18, a phytoplankton bloom reduced the amount of phosphate at both the 7.5 and 15 meter levels. It appears from the phosphate minimum of $0.64 \mu \mathrm{gm}$ at/liter on January 18 at the 15 meter level, that the bloom had originated there and had moved up to the 7.5 meter level where it was collected. The larger volume/liter of phytoplankton that was taken at 7.5 meters supports this hypothesis. The phytoplankton apparently remained at the 7.5 meter level during the subsequent week since the 15 meter 
level returned to the previous weeks' concentration, but the 7.5

meter level continued to decrease in concentration due to removal by phytoplankton.

The onset of the second surge of the upwelling was more evident at Station 2 than at Station 1. Figure 12 shows a very large bloom on March 22 at 7.5 meters and this corresponds rather nicely with the sharp minimum of phosphate at that level on March 22 (Figure 9). On this date the phytoplankton at 15 meters did not show such a large increase and the phosphate level at this depth correspondingly indicated a slight rise in value. On April 1 a very sharp increase in the phosphate concentration occurred at a11 levels due to upwelling. The next week showed a decrease of phosphate accompanying the increase of phytoplankton at those levels.

Station 3 curves given in Figure 10 11kewise follow the low Oceanic Period of November with increases during the Davidson Current Period due to increased seaward transport of runoff and mixing with the lower nutrient-rich layer. Since phosphate concentration increases with depth (Raymount, 1963), it is reasonable to assume that mixing with deeper layers further seaward will cause an increase in phosphate concentration that would place it on an equivalent level with the two more shoreward stations. Another point to consider is that the maximum concentration level during the Davidson Current Period was $1.1 \mu \mathrm{gm}$ at/liter and this persisted for three or four weeks. Possibly this is the level of phosphate concentration derived from a uniformly mixed water layer, and represents the maximum resource level of nutrients within the Bay. When Figure 8 is compared with Figure 10 one sees immediately that the shoreward station acquires 
this leve 1 at $1.0 \pm 0.1 \mu \mathrm{gm}$ at/liter more rapidly than station 3. Probably a combination of shore influence, current concentration, vertical mixing, and sluggishness of water at station 3 was responsible for the curves given for the three stations.

The first sign of a possible upwelling feature was on February 15 (see Figure 10), when the phosphate concentration made its initial rise. In Figure 13, the increased concentration of phytoplankton that occurred during the following three weeks accounts for the decreased levels of phosphate found on March 15 and 25. The second surge of the upwelling on April 1 was not utilized by the phytoplankton population; consequently, a high phosphate level was established. The decrease that occurred on Apr11 8 is unexplained by the curve given in Figure 13. No phytoplankton bloom occurred to reduce the phosphate level this much. There appears to be no immediate explanation for this inconsistency of phosphate and productivity curves. On April 15 an increase in phosphate was experienced followed by a decrease on Apri1 22. Again, no phytoplankton bloom occurred at either level (Figure 13). The fact that the stations were occupied during perlods of heavy overcast and precipitation, alternating with bright clear days, could account for near surface vertical movement of the phytoplankton. 


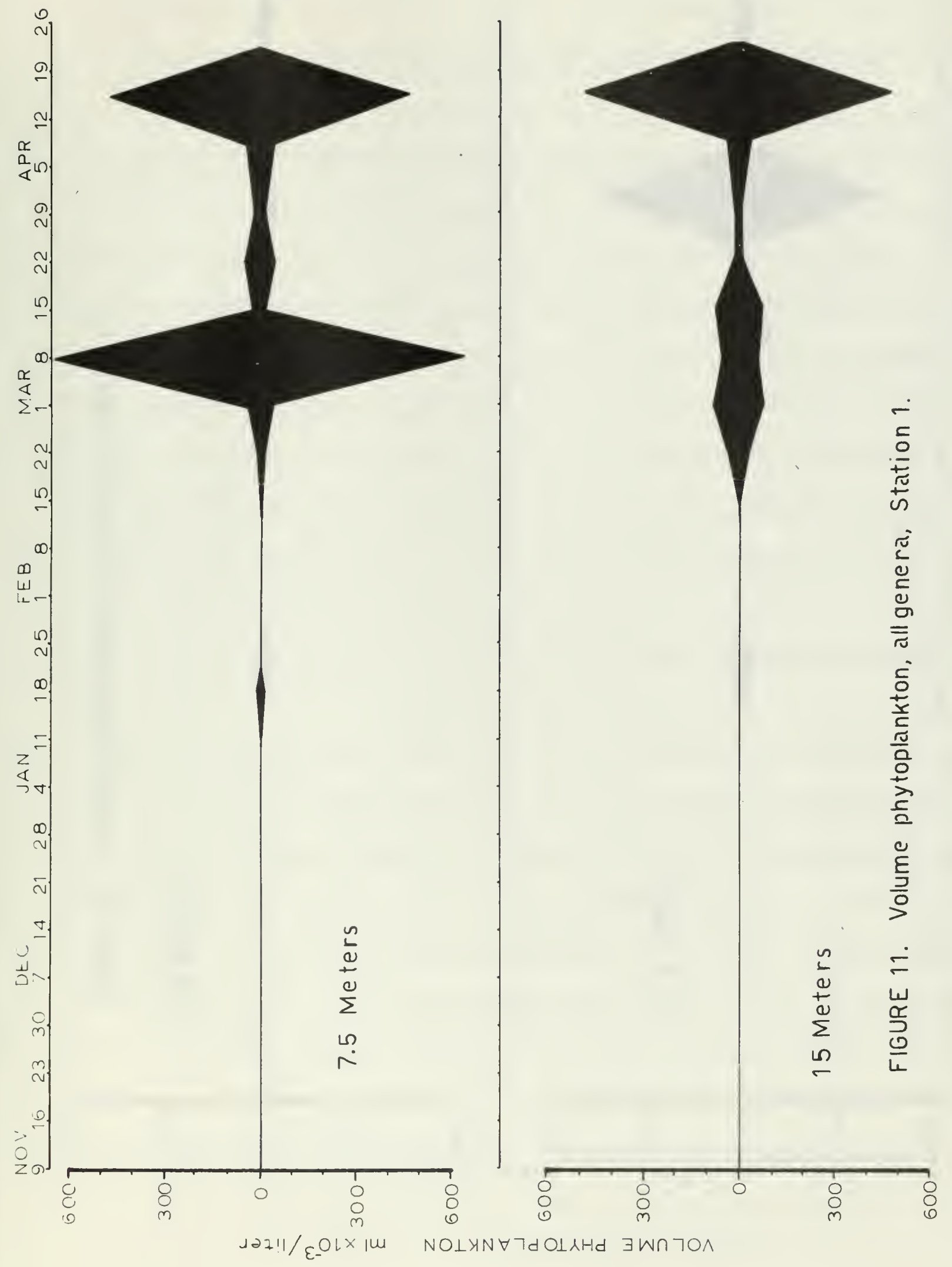




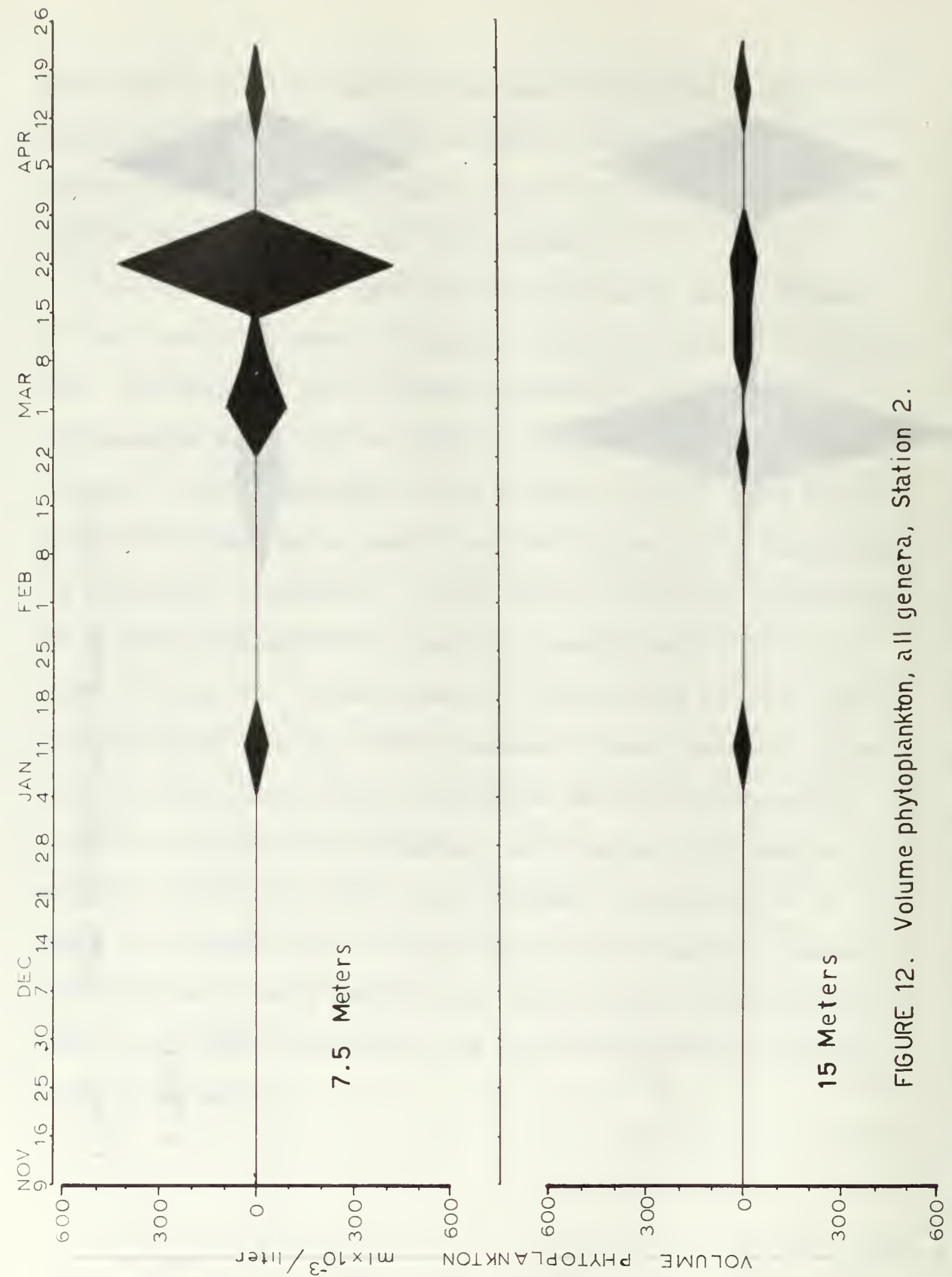




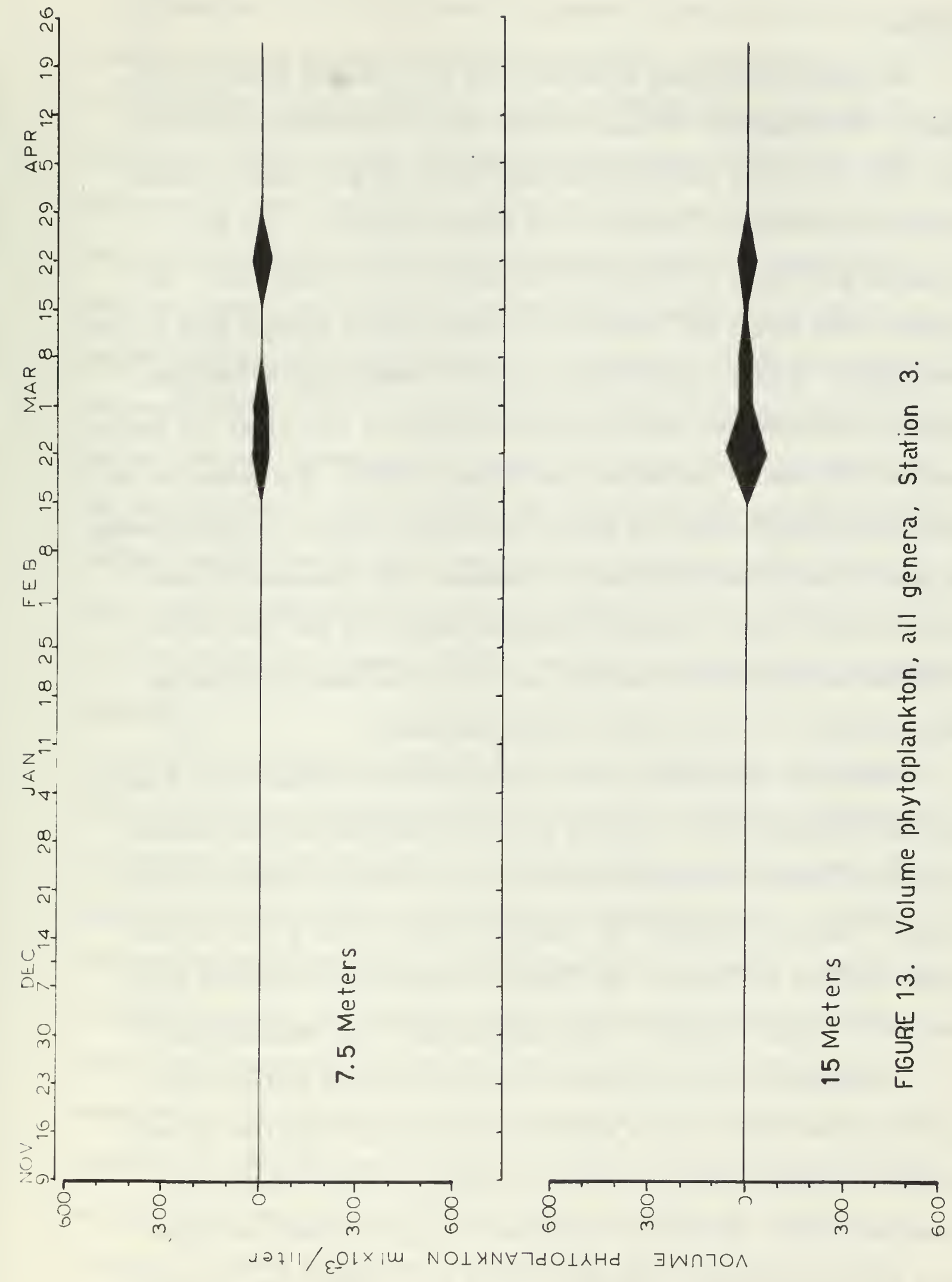




\section{SILICON}

As results show, and as polnted out by Bolin and Abbott ( 96.3$)$, most phytoplankton utilize silicon that is dissolved in the sea for body structure, primarily the cell wall. A good index of ph:toplankton productivity, then, is the silicon profile of the Bay. Sampling procedures were exactly the same as for phosphorous. The samples were frozen for storage in 4 ounce plastic bottles with chloroform added. Analysis occurred at most ten weeks after collection. Analysis followed the siliconmolybdate reduction with metol and oxalic acid as outlined in Strickland and Parsons (1965). The choice of the metol-oxalic acid reduction method was used in order to take advantage of the intense blue color that is produced. The procedure is much less sensitive than a stannous chloride reduction, but the latter requires exacting time intervals and the yellow color produced is more difficult to resd on the spectrophotometer.

Extinction units were read at $810 \mathrm{~m} \mu$ on the Beckman DK $1 \mathrm{~A}$ RecordIng Spectrophotometer. Units of percent transmission were recorded graphically when the machine was set with fixed split image and wave length. Analysis accuracy was somewhat greater than $\pm 0.25 \mu \mathrm{gm}$ at $/$ liter using $10 \mathrm{~cm}$. cells. The limit of detection of reactive $\mathrm{sili-}$ cate was $0.1 \mathrm{\mu gm}$ at/liter. Technique accuracy was considered good. A standard of fused arhydrous silicic acid and sodium carbouate was used. Each run of samples utilized the comparlson of two separate standard curves in order to correct fior amy machine or technique error. It should be pointed out that on both occasions that analyses were made, standard curves were equal, thus assuring the accuracy of the results. 
Dissolvable silicon is usually present in the sea as the silicate ion and appears variably in the Bay according to the oceanographic regime in process. As in the case of the nutrients, the Oceanic Period brings silicon depleted waters in from the open sea, and one would expect very minimal values. At the onset of the Davidson Current Period, the values may appear increased but will maintain a relatively low concentration during the period. During the Upwelling Period values of silicon will increase during the early months, due to the silicon rich deep waters of the Monterey Canyon, and will decrease to a summer low due to the utilization by the phytoplankton. During periods of grazing by the zooplankton, the silicon content may increase due to the rapid regeneration in the sea. This regeneration of silicon is definitely more rapid than that of other nutrients (Raymount 1963), and at times produces an irregular profile.

A gross analysis of Figures 8,9 , and 10 indicates the presence of all three oceanographic periods. A very low silicate concentration is observed through November at all depths and at all stations. Beginning in early December and continuing through January, a gradual increase to 20-30 $\mu \mathrm{gm}$ at/1iter concentration for station 1 and 2 , and a smaller increase at Station 3 marks the Davidson Current Period. During the latter part of January and the first week of February, a decrease in concentration value is noticed at all stations due to the slackening of the current and to the utilization by the small numbers of the phytoplankton present. On February 8 the first increase in silicate is noted signalling the beginning of an Upwelling Period. As with other parameters, the sllicate concentration is then decreased 
or maintains the inftial upwelling level until late March when a second and much stronger surge of upwelling is seen. Again the usual continual increase from the onset dates of early February is retarded and reversed by phytoplankton blooms occurring in early March.

The small phytoplankton bloom that occurred on January 25 at Station 1 is not reflected strongly in Figure 8 in the silicate curve. Figure 11 indicates that the bloom is only measurable at the 7.5 meter level, but Figure 8 shows only a slight decrease in the silicate value on that date. The bloom that occurred on March 8 at the 7.5 meter level and to a lesser but more stable degree at 15 meters accounts for the decreased value of silicates during that time interval as shown in Figure 8. On March 25 the sudden surge downward at 15 meters corresponds to the decrease of phytoplankton at that level (Figure 11). The sudden massive increase in silicates brought on by the upwelling was the response at those levels to the continual small phytoplankton population. A second massive increase in phytoplankton at both sampling levels accounts for the sudden drop in silicate at the 7.5 and 15 meter levels on April 15 (Figure 11). Station 2 shows the same low Oceanic Period concentration as Station 1. The trace of Figure 9 compares generally with Figure 8 throughout until the second upwel1ing surge. The phytoplankton bloom that occurred on January 11 at both levels (figure 12) accounts for the $10 \mu \mathrm{gm}$ at/liter decrease in silicate that occurred on the same date (Figure 9). Since the bloom was not sustained, the values of silicate rose again in the next two weeks, only to decrease during the pre-upwelling period. On February 8, at all three levels 
(Figure 9) an increase in silicate concentration was noted which signalled the upwelling onset. Again the surge was not strong enough to continue, and decreasing values were noted due to utilization by the minimal numbers of phytoplankton organisms. Figure 12 shows three bloom areas on the profile at both the 7.5 and 15 meter levels. The first, occurring on March 1, accounts for the continual decline of the silicate curve after initial upwelling. Before the upwelling can replace the utilized silicate totally, another stronger bloom occurs on March 15. It is after this bloom that the first large increase of silicate occurs (Figure 9). This level is maximized at the surface at $62 \mu \mathrm{gm}$ at/1iter on April 1. Subsequent losses and gains are the product of the third bloom at the station occurring on April 15.

Station 3, shown in Figure 10, gave a more stable profile during both the Oceanic and Davidson Periods. No bloom occurred, (Figure 13) during January as it did at the other two stations. The upwelling of early February was noted only slightly on February 22 at 7.5 and 15 meters. This was probably due to the large dilution at the more seaward station. Responses to the second surge of the upwelling could be seen as early as March 15 at 7.5 and 15 meters (Figure 10). This ability to see the effects of upwelling was due to the fact that the phytoplankton blooms that occurred on February 22 and March 1 had died out somewhat as indicated by Figure 13. The larger, persistant bloom at 15 meters during the interval of February 22 to March 8 supports the February upwelling date.

The trend of a seaward moving concentration of silicon, occurring in early January, (Figure 8) and continuing to sea to 
terminate on February 1, (Figure 10) should be discussed. A characteristic of the Davidson Current Period is the shoreward movement of ourface water and a subsequent piling of water along the shore. This requires a subsurface seaward movement of the near shore waters. It is entirely possible that a mass of water having a high silicon content may move seaward as a concentrated body at some subsurface depth. This seems to be shown in the silicon profile of Figures 8 , 9, and 10. On January 4 at Station 1 the body moved through the 7.5 meter level with some indication of the high level of concentration at the 15 meter level. At this time the concentration was $37.8 \mu \mathrm{gm}$ at/liter at 7.5 meters and $25.5 \mu \mathrm{gm}$ at/11ter at 15 meters. Both values were well above the mean for the period. On January 25 at Station 2 a sharp maximum of $30.2 \mu \mathrm{gm}$ at/11ter was noted at the 15 meter level with much smaller rises at the two upper levels as shown by Figure 9 . In Figure 10, the sharp maximum is noted on February 1 at 15 meters, but at this station the concentration value had increased somewhat to $42.5 \mu \mathrm{gm}$ at/liter. Like the other two stations, this peak was in sharp contrast to the trend of the curve. These data showing station to station movement over a time interval may be used to support the seaward movement of nearshore waters caused by the Davidson Current. 
PHYTOPLANKTON

SAMPLING PROCEDURE

One of the main objectives of this study was dividing the 15 meter layer studied by Bolin and Abbott into two layers of equal depth, and relating the genera of phytoplankton found at each stratification to the parameters studied. Due to Iimitations imposed by analysis time and boat scheduling, only two depths within the upper 15 meter layer were sampled; on each cruise at each of the three research stations, Clarke-Bumpus hauls were made at 7.5 and 15 meters. A net of 175 threads/inch (size 20) was used to insure the sampling of the smallest identifiable phytoplankton organisms. Use of the Clarke-Bumpus sampler was required in order to sample only the two depths of interest. In addition to providing uncontaminated, layered hauls, the Clarke-Bumpus sampler is fitted with an impeller volume counter so that by simple calculations one can obtain the approximate volume of sea water filtered. The phytoplankton hauls were preserved by the addition of formalin. Storage was in glass jars.

The preserved samples were placed in graduated cylinders and allowed to settle for 12 to 24 hours. A wet volume of the plankton was then read to the nearest milliliter. The sample was then decanted to a total volume (plankton and fluid) of $100 \mathrm{~m}$. This reduction of the volume to an accurate total volume was not necessary to the research project but was provided for subsequent utilization of the collected data. After agitating, a one milliliter sample was withdrawn with a Stemple pipette and placed on a rafter tray for counting. The sample was evenly dispersed on the counting tray and an estimation was made of the percent of the sample that was phytoplankton. 
This percent volume was used to calculate the volume of phytopiatidton per liter of sea water (Figures 11, 12 and 13). The organisms jin the phytoplankton were identified to genus and counted. This numerical sum of all phytoplankton counted was used as a base in evaluating the percentage count for each genus in the total population of phytoplankton. The total number of phytoplankton organisms was very small during the winter months but during blooms a one milliliter sample would often contain hundreds of thousands of plants. When these extremely concentrated hauls were taken, dilutions of $10: 1$ and $5: 1$ were made for ease of counting. The whole milliliter sample was tallied regardless of total numbers present.

No attempt was made to identify the organisms beyond genus. A very detailed study with identification to species would require the aid of a trained taxonomist. The Naval Postgraduate School posesses portions of each sample so that further identification or use may be made of the initial research. A discussion of the phytoplankton in general has been given in the nutrient section. Since the research project had as a prime objective the stratification analysis of phytoplankton, a discussion of the results given by the generic identification should provide information as to the preference of the organism for the environment at each depth. 
Several investigators have made detailed analyses of the phytoplankton present in Monterey Bay. Cupp (1943), in her manual on diatoms, references a work in 1930 by Bigelow and Leslie. From this early date comprehensive studies have been made in the gross population of the Bay. In the Hopkins paper (Bolin and Abbott, 1963), reference is made to the work done by Dr. Enrique Balech who made species identification on the Hopkins samples. The present study resulted in the counting of 21 individual genera which included 5 genera of dinoflagellates and 16 genera of diatoms. Three genera, Dinophysis, Lithodesmium, and Schroderella, were not listed in the Hopkins paper but were identified in the present study. While their presence in the previous studies may not have been large enough to report, sufficient numbers of the three genera were found during the present study to regard them as important members of the plankton community. Figures $14 a$ and $b, 15 a$ and $b$, and $16 a$ and $b$ show the percent of each of the genera relative to the total phytoplankton count. The accordion graphs 1 ist the genera in decending order of maximum peak attained during the research period. The dominant form during the period was the genus Chaetoceros, followed by the genus Rhizosolenia. The other genera made up from ten to sixty percent of the total count depending upon the oceanographic regime and nutrient supply. Ten of the genera normally were present only in trace amounts. CHEATOCEROS

The genus Chaetoceros is generally associated with cold upwelling waters, but it is present during most of the year, even in periods of very low plankton hauls. During the early weeks of November, the 
STATION 17.5 meters

STATION 115 meters

NOV DEC JAN FEB MAR APR NOV DEC JAN FEB MAR APR

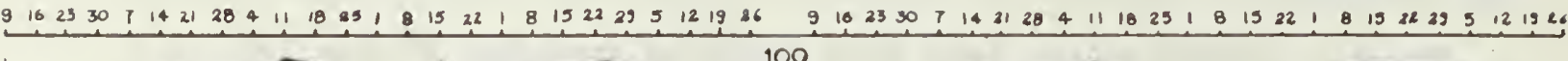
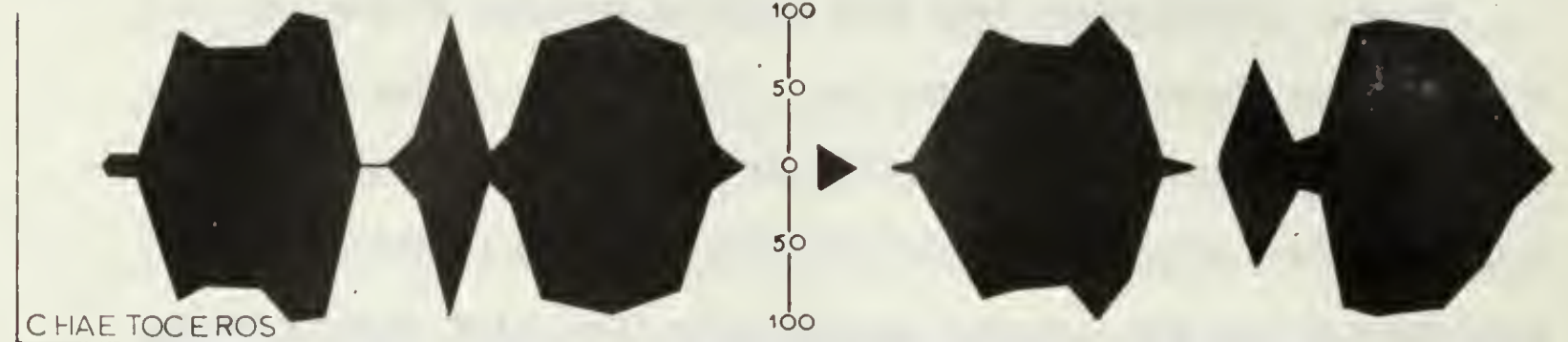

RHIZOSOLENIA

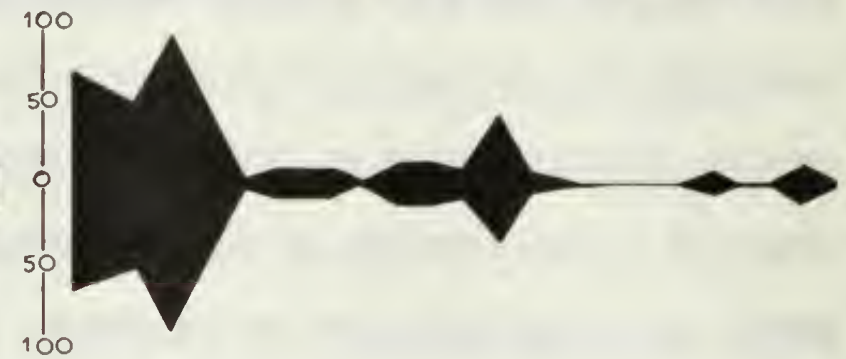

PERIDINIUM
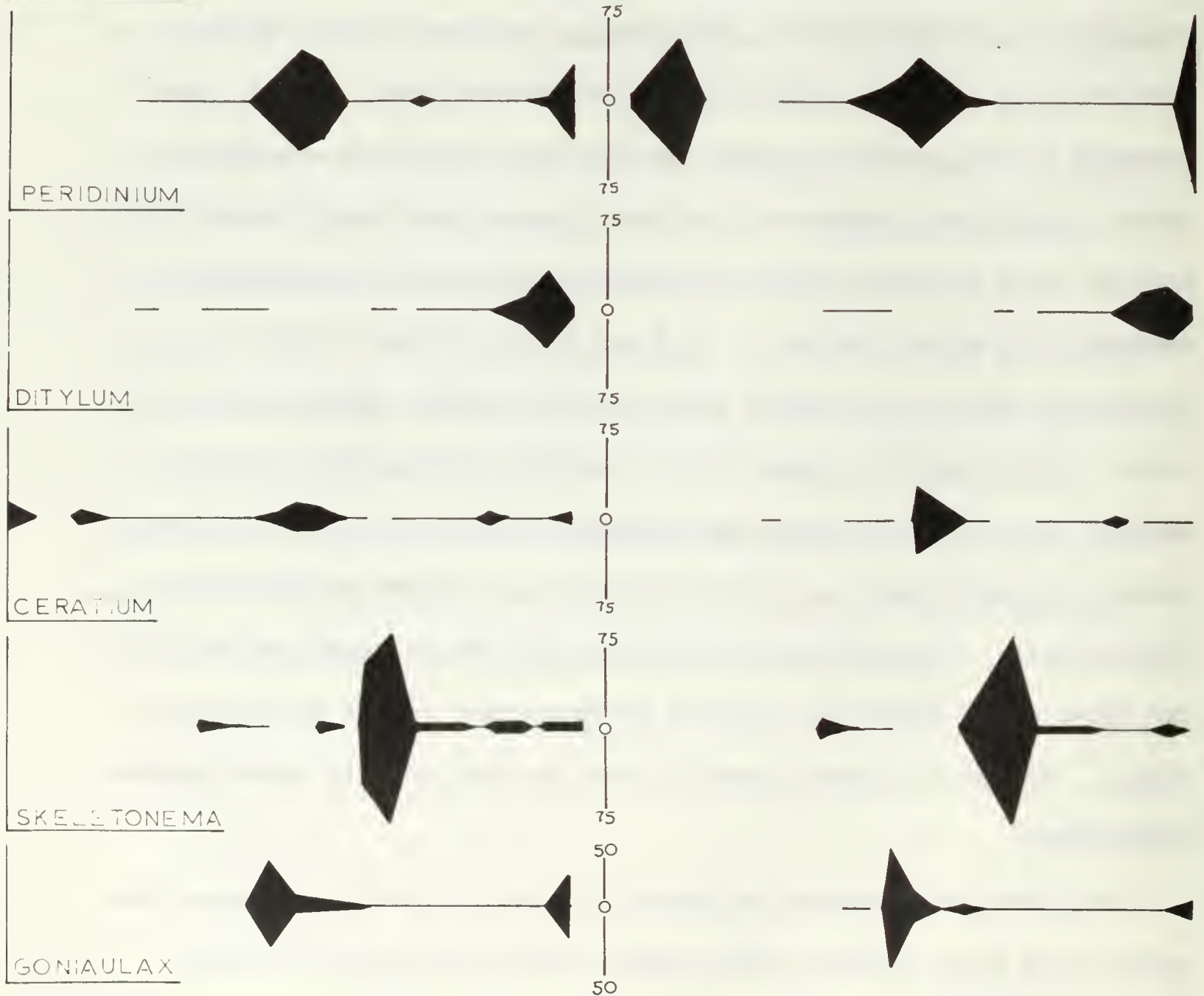

FIGURE 14 a. Relative abundance of generą expressed as percent of total count. 


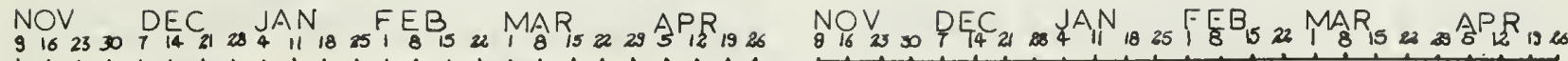



THIALAS SIOSIRA
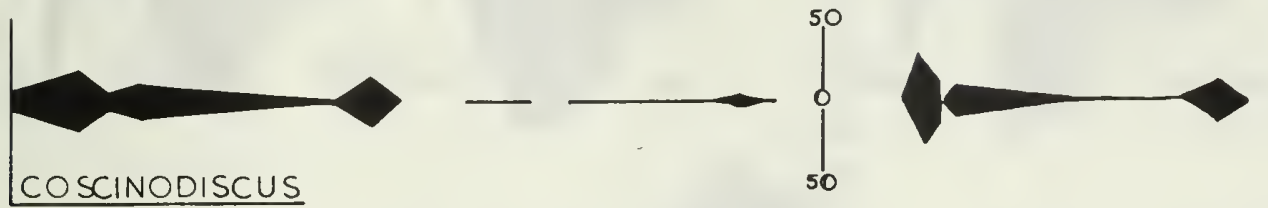

COSCINODISCUS

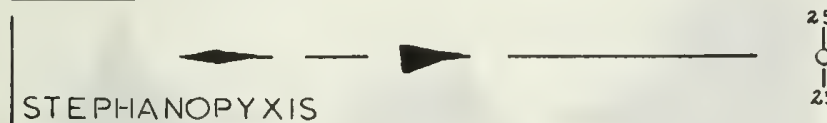

is
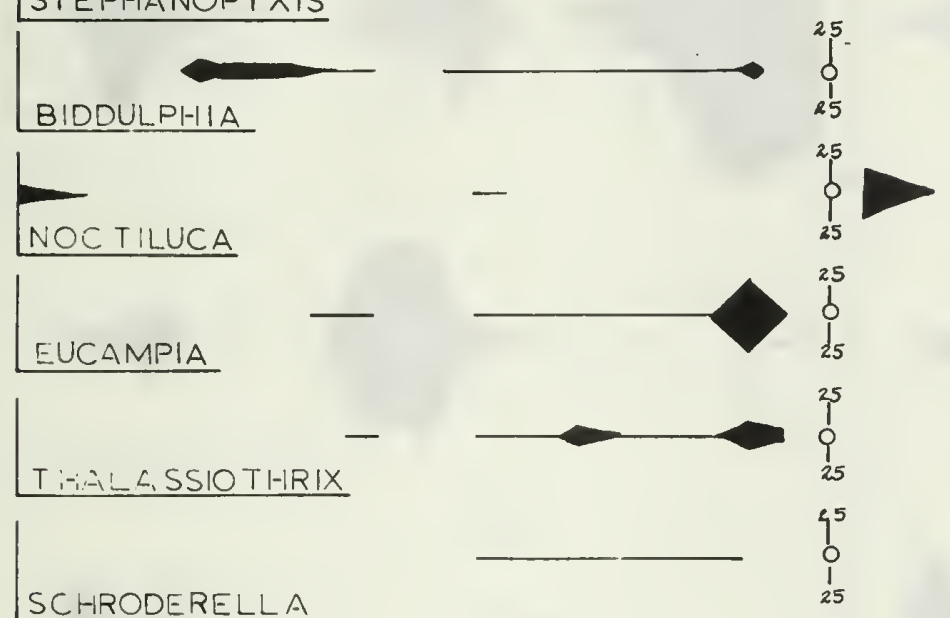

$4^{5}$
1
1
25
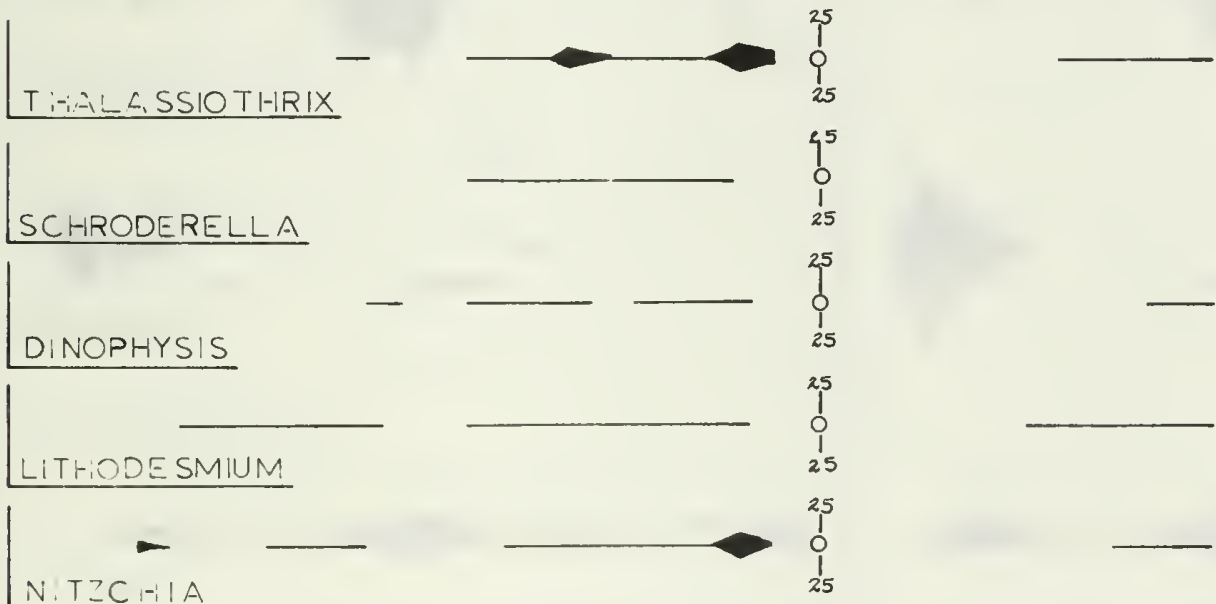

ASTERIONELLA

THALASSIONEMA

COSCINOSIRA

FIGURE 14 b. Relative abundance of genera continued. 


\section{STATION 27.5 meters}

STATION 215 meters

NOV DEC JAN FEB MAR APR NOV DEC JAN FEB MAR APR

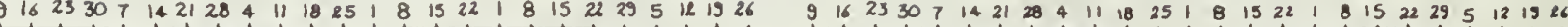

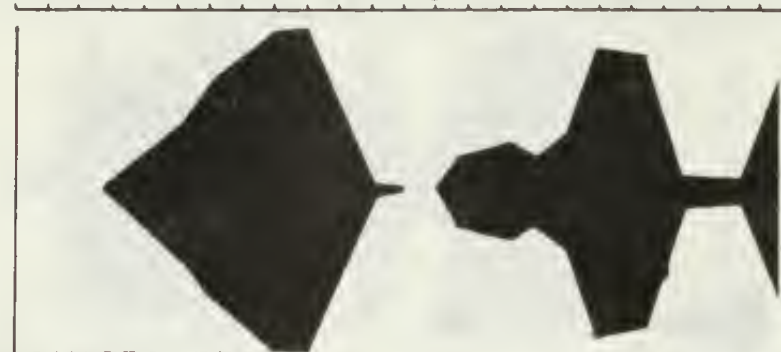

CHAETOCEROS

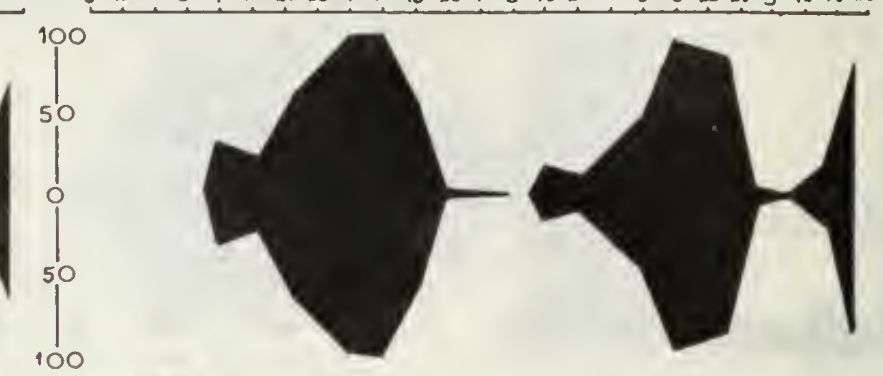

RHIZOSOLENIA
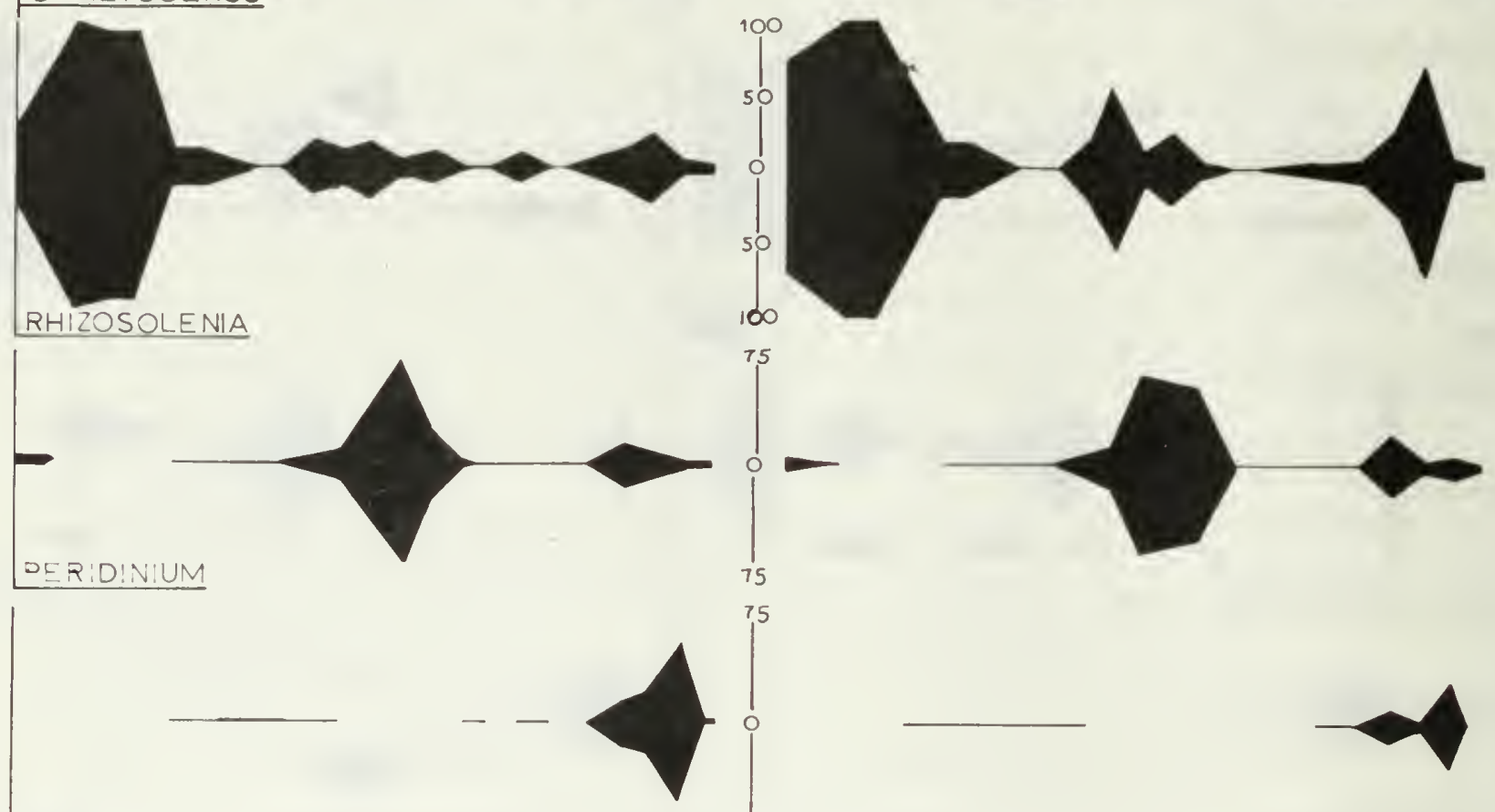

\section{DITY:UM}
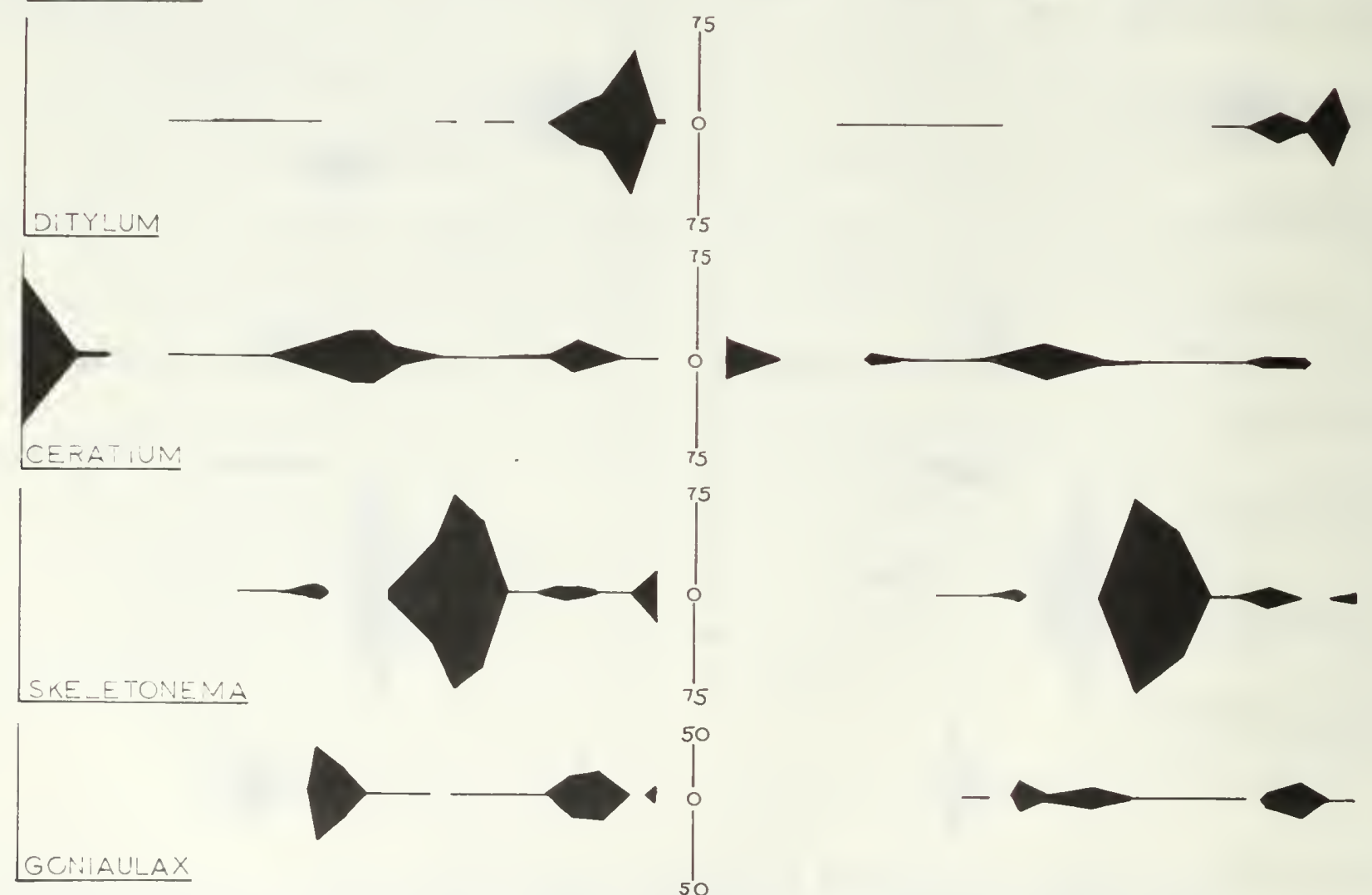

FIGURE 15a. Relative abundance of genera expressed as percent of total count. 
STATION 27.5 meters STATION 215 meters NOV DEC JAN FEB MAR APR NOV DEC JAN FEB MAR APR

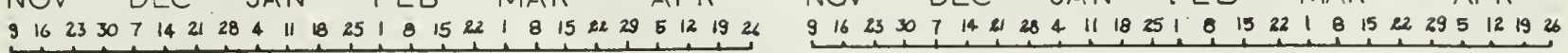
THALASSIOSIRA
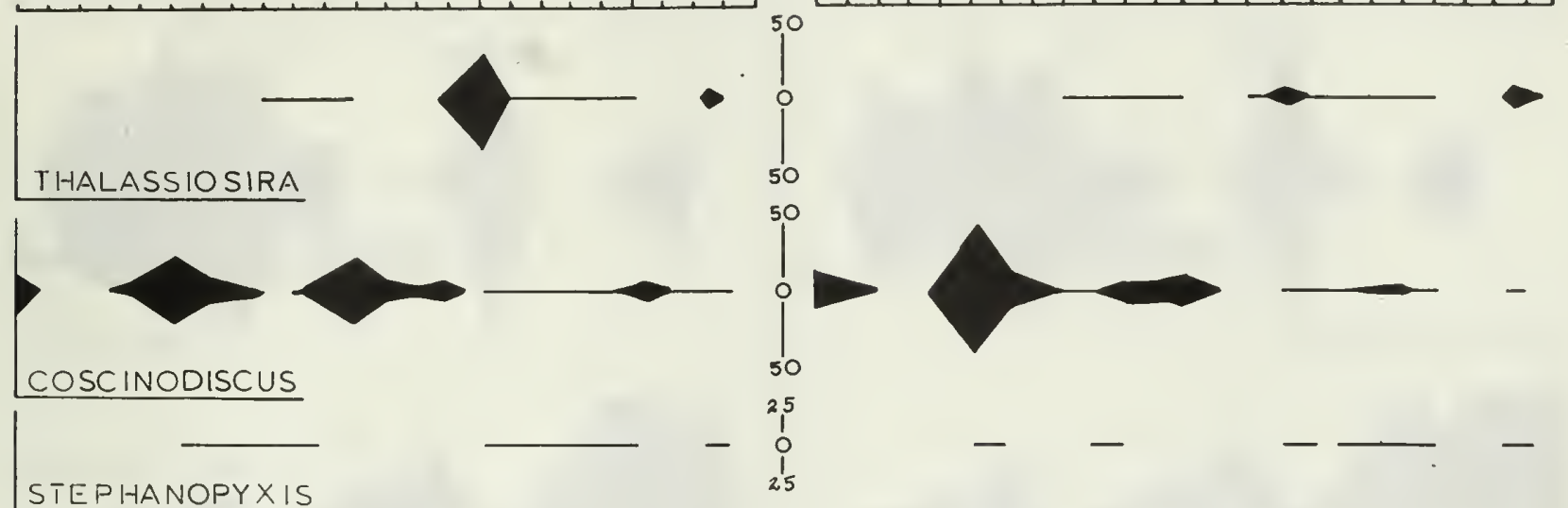

25
1
0
1
25
25
1
1
25

B:DDULPH-11A
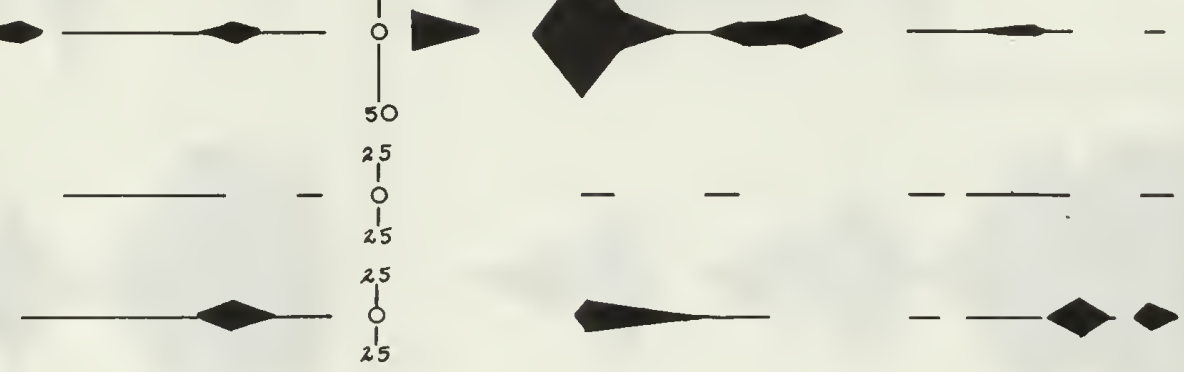

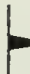

NOC TILUCA
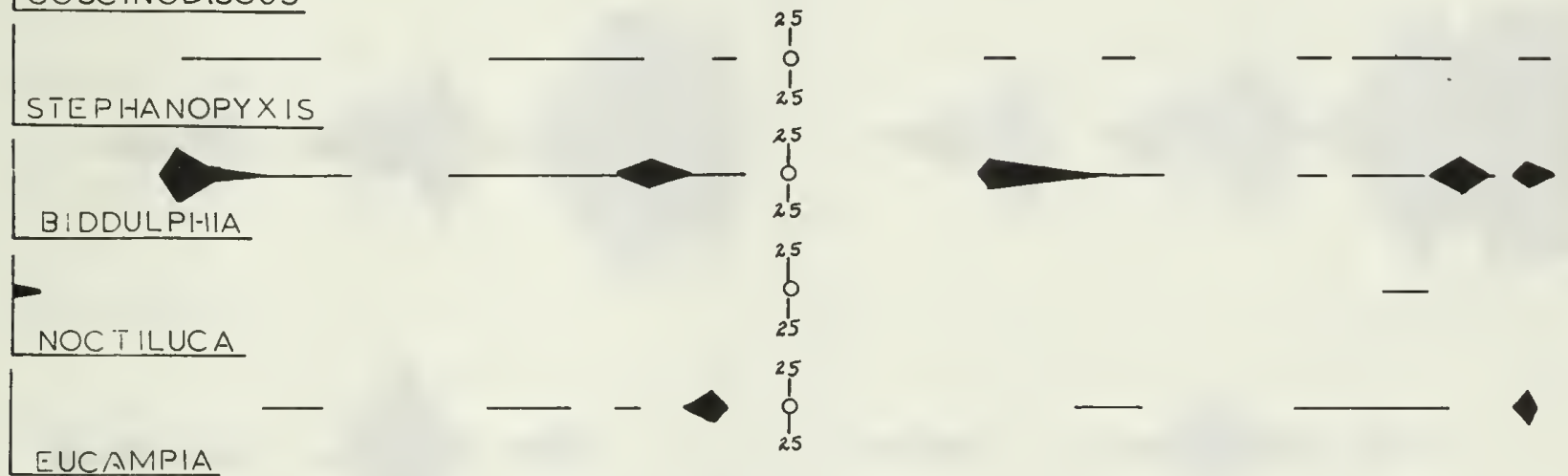

LEUCAMPIA

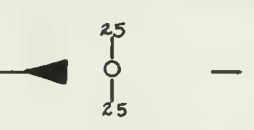

THALASSIOTHRIX

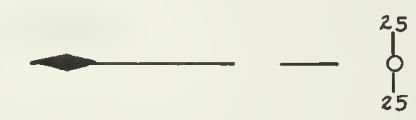

SCHRODERELLA

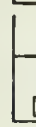

DINOPI-IYSIS

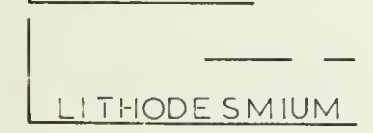

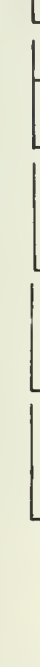

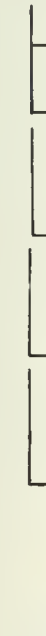

NITZCHIA

ASTERIONELLA

THALASSIONEMA

COSCINOSIRA

FIGURE 15b. Relative abundance of genera continued. 
NOV DEC JAN FEB MAR APR NOV DEC JAN FEB MAR APR

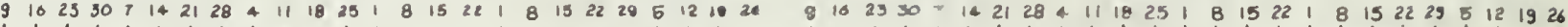
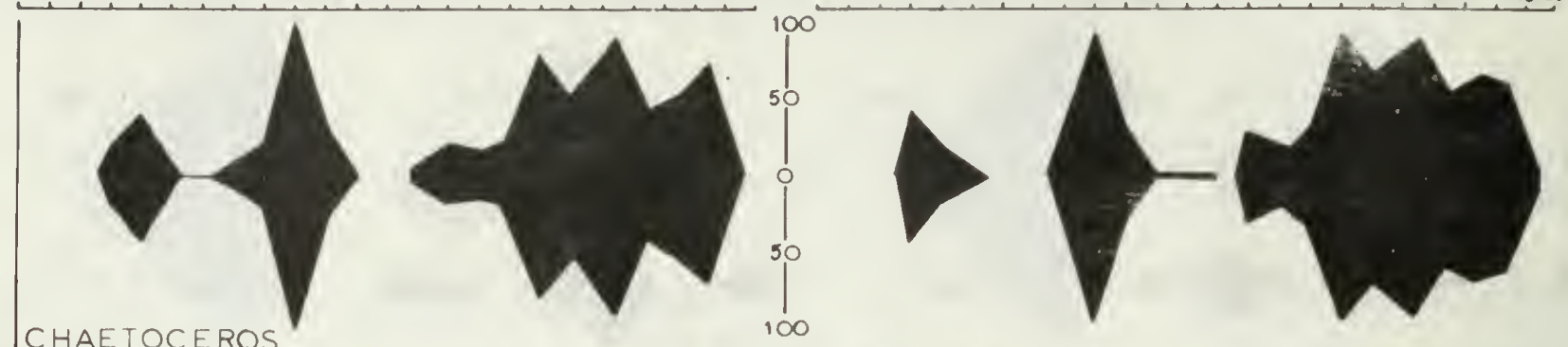

CHAETOCEROS
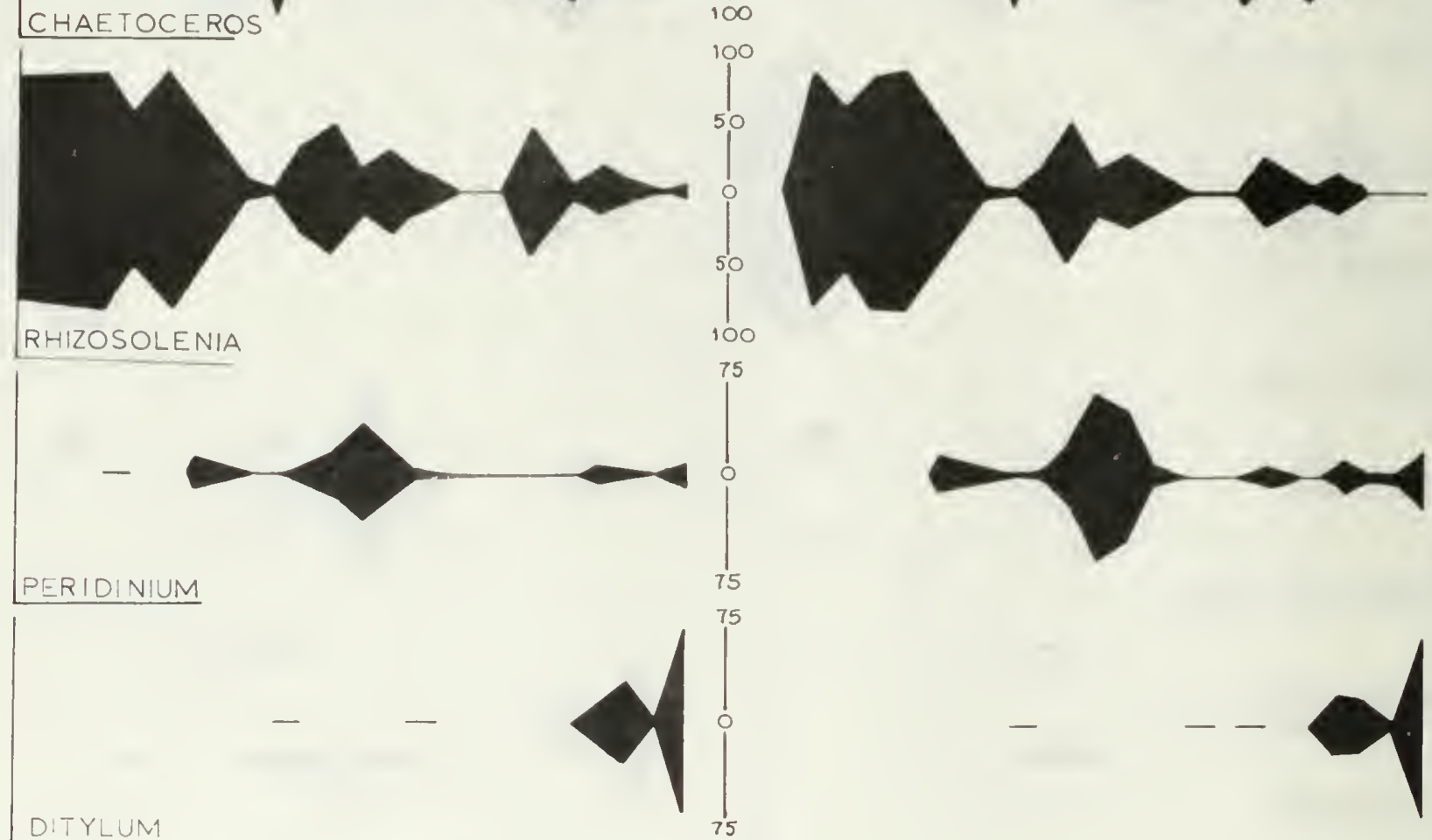

\section{DITYLUM}
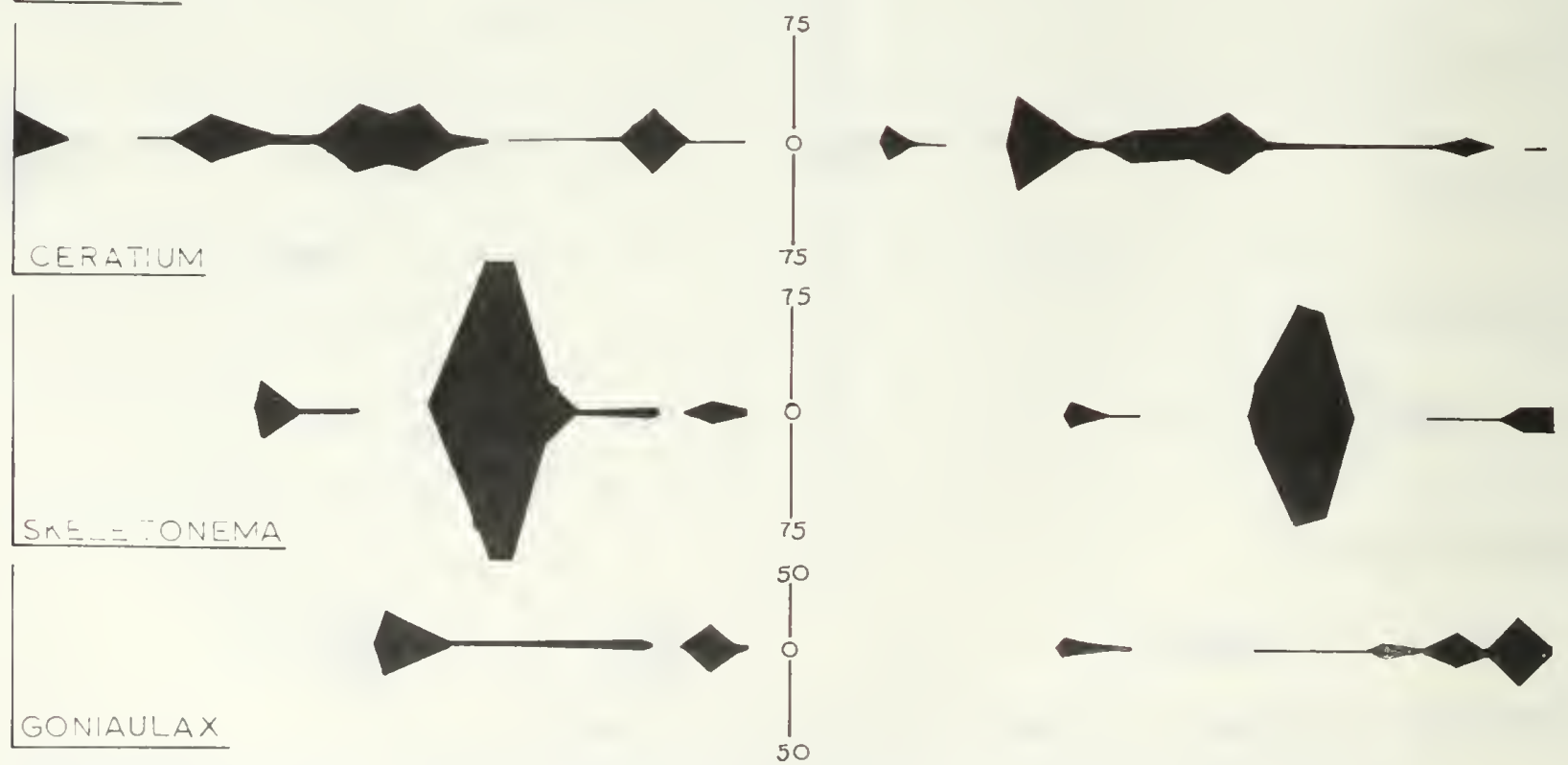

\section{.}

FIGURE 1Ga. Relative abundance of genera expressed as percent of total count.
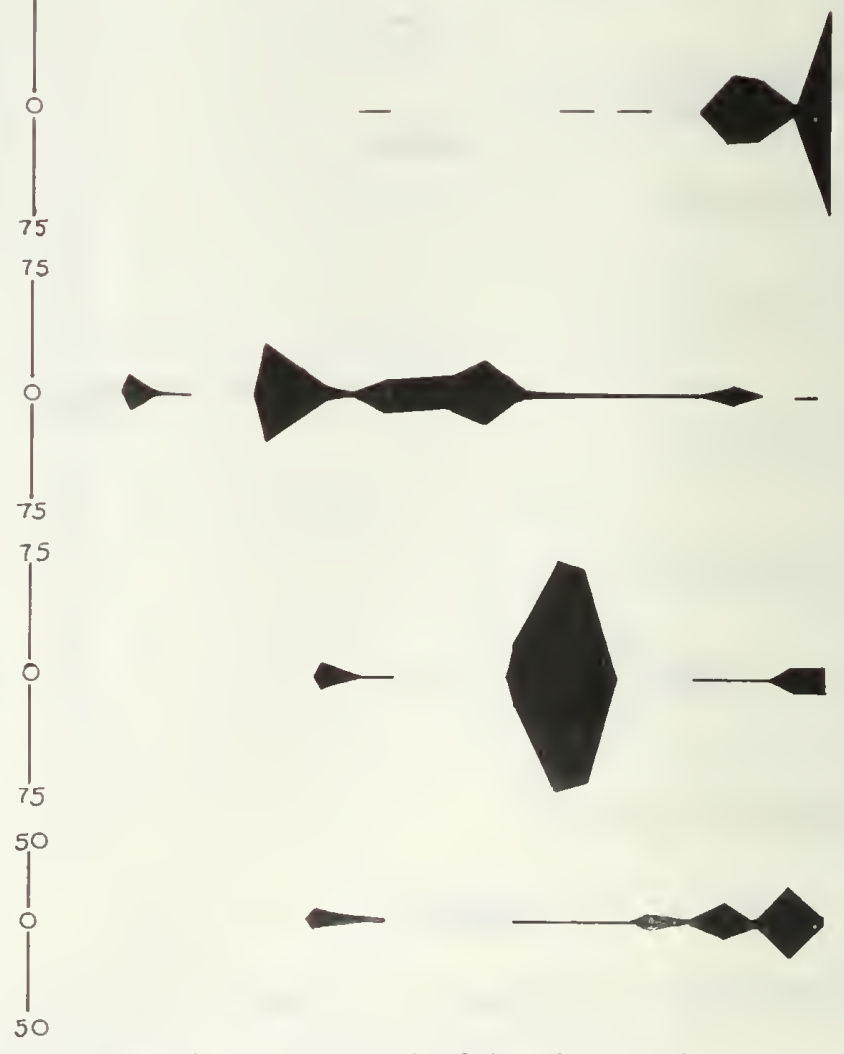
STATION 37.5 meters

STATION 315 meters

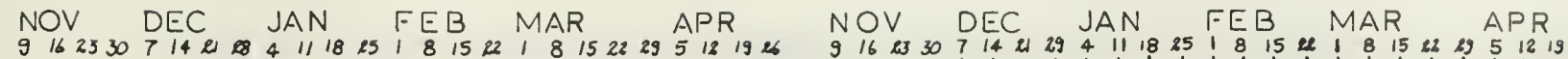

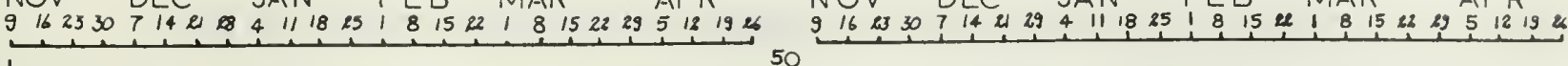
THALASSIOSIRA
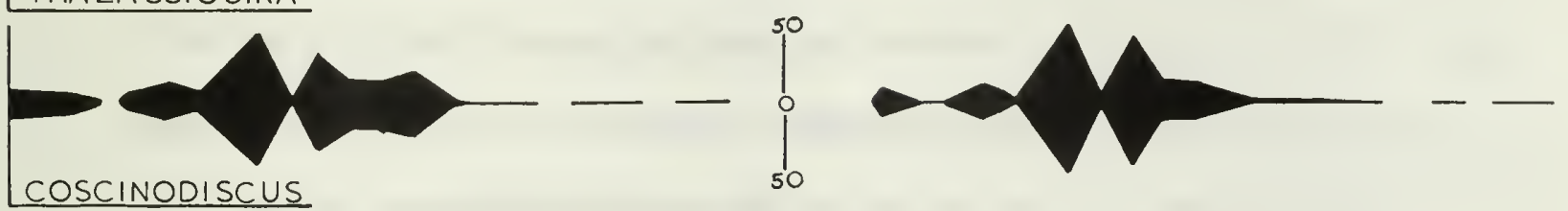

COSCINODISCUS


ASTERIONELLA

THAL ASSIONEMA

LOSCINOSIRA

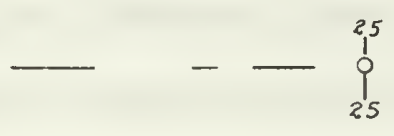

$$
\begin{aligned}
& \begin{array}{l}
2,5 \\
9 \\
25 \\
25
\end{array} \\
& \begin{array}{r}
25 \\
-\quad 9 \\
-\quad 9 \\
25
\end{array}
\end{aligned}
$$

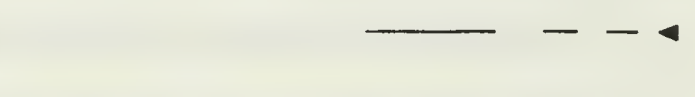

\section{,}




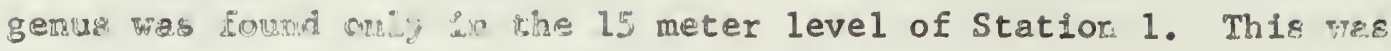
probabiy hecsuse of that currient supply that may have been form. th the Inshore riter. 7 gure 8 gives a phosphate concentration of about $1.0 \mu$ gin at/124et on November 9 but it then diminishes rapidly. Chaetoceros aiso dinlnished during this interval and was absent during the following weaks. At the onset of the Davidson Current Period in early December Chaesoneros became the dominant genus, utilizing the increased levele of phosphate and silicate. Station 1 was undoubtly influenced most strongly by the vertical mixing. The increase occurs earliest as both the 7.5 and 15 meter levels of Station 1 on November 30. A a 1-12at licreage was noted at the 7.5 meter level of Station 3 or that date bit ir subsequent weeks did not show the continual doximanes se seen st the other two stations. Figures 11, 12, and 13 indicate the populbtors is st1l1 very small and although Chaetoceros Is the dominant E., bloom did not occur as in later nutrient Influxes.

Figure 12 indicaces an attempted bloom at Station 2 by the phytoplarikiton on January 11 at both the 7.5 and 15 meter levels. A Similar attarps was made on January 18 at 7.5 meters at Station 3 . The Chactoseros aures (Figures $15 \mathrm{a}$ and 16a) indicate that the dominance by chaetoceras was on the wane and the bloom cannot totally be attributed to the presence of Chatoceros. Of interest is the fact that 3 tateon 3 Iindicares an increase of dominance by the genus on that date but that no bloom was registered (Figure 13).

The nesc large perind of dominance by Chaetoceros came at all stations on rebruary 8 , the date given for the initial surge of upre112ag. Whe ounirstes at 211 stations was indicated at the 7.5 
meter level with the curve on the following week indicating an increase at the 15 meter level. The dominance did not produce a bloom, as is indicated by Figures 11,12 , and 13. The genus diminished in dominance due to depletion of nutrients and weak upwelling, but increased both in dominance and quantity during the strong upwelling on or after March 1. Station 3, at both the 7.5 and 15 meter levels, indicated the occurrence of blooms first, as indicated in Figures 13 and 16a. A late April decrease is due to the competition offered by dinoflagellates and other genera of diatoms that are able to increase only in the presence of nutrient rich waters. Both Station 1 and Station 3 show the competition for food supply, but Station 2 gives an increase of Chaetoceros, (Figure 15a) indicating the absence of the competitive genera.

RHIZOSOLENIA

The second most abundant genus throughout the research period is a form that is capable of surviving in low concentrations of nutrients. Rhizodolenia appears as the dominant form when Chaetoceros has been suppressed] on every occasion except two when the dinoflagellate Peridinium and the pre-upwelling diatom Skeletonema dominate. During the Oceanic Period of November very low values of nutrients were available at all stations at every level. On November 9 Rhizosolenia was the dominant genus at all sample points except the 7.5 meter level of Station 2. The dominance continued at all stations until the Davidson Current began in early December. The decrease in December is due to the increased dominance of Chaetoceros. In late January when the nutrient level began to drop, (as indicated in Figures 8, 9, and 10) Rhizosolenia showed a brief dominance. The 
dominance was most marked at Station 1, at both depths; at Station 2 at 15 meters; and at Station 3 at both depths. The genus then decreased to remain at a rather low level of importance during the rest of the research period. The genus made a brief rally during the upwelling and managed one more peak of dominance on April 8 at Station 2 at 15 meters. This singular dominance was correlated with a nutrient loss as given in Figure 9 at both the 7.5 and 15 meter levels.

\section{PERIDINIUM}

The dinoflagellate Peridinium occurred as a dominant form only during periods when Chaetoceros or Rhizosolenla were scarce. The occurrence of dominance was often paralleled with increases of Rhizosolenia Indicating Peridinium was able to Increase despite low concentration of nutrients.

Initially during the Oceanic Period there was one very sharp increase of Peridinium at 15 meters at Station 1 but no other station or depth indicated this increase. On February 8 a11 three stations at all depths, (except at 7.5 meters at Station 2) indicated an increase of the genus. The maximum values were random for each depth but a general pattern of maximum dominance is shown at the 15 meter level in Figure 14a, 15a, and 16a. One other period of dominance was noted (Figure 14a) on April 22 at Station 1 at both the 7.5 and 15 meter levels. Here again maximum dominance was at the deeper of the two 1syers.

DITYLUM

This diatom has been generally associated with nutrient rich upwelling waters and apprears in the analysis in such waters. The 
genus appeared at a11 stations intermittently, throughout the Davidson Current Period and Upwelling Period when nutrients were available. It appeared only as an effective member of the population during April when upwelling was sufficiently strong to support the several genera requiring a high level of nutrient concentration. The genus appeared strongest at the 7.5 meter level at all stations. Relative magnitude of the various stations indicated that the level reached at Station 1 (Figure 14a) was about 25\% 1ower than at station 2 (Figure 15a) and about 50\% lower than at Station 3 (Figure 16a). CERATIUM

The genus Ceratium is generally considered an open ocean member of the plankton, appearing in Monterey Bay only during the surface water movement periods of the Oceanic and Davidson Current Periods. On November 9 at Station 2 at the 7.5 meter leve1, a maximum for. the genus occurred. Over $50 \%$ of the phytoplankton at this station consisted of Ceratium. The genus appeared intermittently throughout the research period with increases occurring only during periods of maximum surface water movement. Figure $14 \mathrm{a}$ shows that the genus is present most comonly at the 7.5 meter leve1. Figure 15 a shows the continuing trend for the maximum appearance in the 7.5 meter leve1, but Figure 16 a indicates a more uniform appearance at both depths. When Figures 14a, 15a, and 16a are compared it is seen that the genus is of greatest importance in the population at station 3. Increases of importance have not been directly associated with nutrient fluctuations. 
SKELETONEMA

The genus Skeletonema is generally used as an index for upwel1ing because of its ability to utilize the minimal increases of nutrients that are generally present. During the research period the genus appears only once as the dominant form at each station. The time of occurrence varied, seaward to shoreward.

On February 22 at Stations 1 and 2 a maximum of nearly $75 \%$ of the total population was recorded at both the 7.5 and 15 meter levels. As seen in Figure 16a, this magnitude of dominance was maintained at Station 3 during the following week, before Chaetoceros could bloom. At station 2 the profile (Figure 15a) indicates a sharp decrease due to the strong productivity of Chaetoceros at this station. Figure $14 \mathrm{a}$ indicates the peak of over $75 \%$ occurred one week later on March 1. This was a very short lived dominance due to the strong Chaetoceros bloom at the station. The genus appears during the Davidson Current and Upwelling Period intermittently during the remainder of the research period with the earliest recorded appearance occurring at al1 stations on January 4. GONIAULAX

The dinoflagellate Goniaulax made an initial appearance in the Bay on January 4 at 15 meters at Station 3. The next occurrence was at the 15 meter level at the other two stations on January 11. The surface waters did not indicate presence of the phytoplankton until two weeks after initial observation at station 3.

A second occurrence, of strength was noticed during April. Here again, the profile of 16 a indicates the 15 meter level of Station 3 is the first to show an increase of the genus. The other level of 
Station 3 and Stations 2 and 1 then showed the increase within a week. There was no direct relationship indicated between the nutrient profiles of Figures 8,9 , and 10 and the occurrence of the Increased numbers of the genus.

THALASSIOSIRA

The genus Thalassiosira appears to be assoclated with only nutrient rich waters. The first recording of this genus was on January 4 at both sampling depths for all stations. The curve given for each station in Figures $14 \mathrm{~b}, 15 \mathrm{~b}$, and $16 \mathrm{~b}$ shows on $1 \mathrm{y}$ one major peak per depth. At Stations 1 and 2 this peak occurred on February 24 at both the 7.5 and 15 meter levels. The increase at station 3 occurred one week earlier on February 15. Figures 8, 9, and 10 Indicate that this is the peak nutrient 1 Imit for the initial upwelling and the curves in Figures $14 \mathrm{~b}, 15 \mathrm{~b}$, and $16 \mathrm{~b}$ indicate the genus requires a sufficient light source as indicated by constant larger volumes of the genus at 7.5 meters. COSCINODISCUS

The diatom Coscinodiscus was present throughout the research period in such significant numbers as to consider it a universal genus. Peaks of nearly $50 \%$ of the population total were reached at Station 2 at the 15 meter level on December 16; at Station 3 at the 15 meter level on December 16; and at Station 3 at both levels on January 4 and 18 . Comparing Flgures 14b, 15b, and $16 \mathrm{~b}$ it appears that the genus is present in greater numbers at station 3 . It appears, generally, at all stations at the 15 meter layer in a larger volume than at the upper layer. 
Stephanophyxis appears to require a nutrient level at least as high as the level produced in Monterey Bay during the Davidson Current Period. The first indication of the genus was on December 16 at Stations 2 and 3 at both levels (Figures 14b and 15b). Continued occurrence was intermittent throughout the remainder of the research perfod with one Individual peak occurring at 15 meters at Station 1 on February 4. The genus has decreasing importance in the population as one moves seaward.

\section{BIDDULPHIA}

The genus occurs at the same time as Stephanophyxis, at the peak of the nutrient level during the Davidson Perlod. The presence of the genus is noted throughout the remainder of the research period with another slight increase occurring with the second large upwe11ing occurrence in April.

\section{NOCTILUCA}

The genus was seen in numbers only during the Oceanic Perlod at Station 1 at both the 7.5 and 15 meter levels, and at 7.5 meters at Station 2 on November 9. Only three other observations of Noctiluca were made at all of the stations during the research period. EUCAMPIA

The genus made its inftal appearance on January 4 at Stations 2 and 3 and on January 11 at Station 1. This was during the peak of the Davidson Current nutrient maximum, indicating that the genus requires a level of nutrients somewhat higher than does the general diatom. Only one major increase was noticed. At Stations 2 and 3 on April 15 a maximum of nearly $25 \%$ occurred at both depths at 
Station 1; a lesser maximum of $15 \%$ occurred at both depths at

Station 2.

THALASSIOTHRIX

Thalassiothrix made sporadic appearances in the Bay. One early reporting was during the Oceanic Period at Station 2 at the 15 meter leve1. The genus then appeared at different times in trace amounts during both the Davidson Current and Upwe1ling Periods. The number of individuals was larger at both depths at Station 1 and at 7.5 meters at Station 2 than at the other depths in the more seaward stations. Increased numbers appeared at Station 1 and 2 during inftial and strong upwelling. SCHRODERELLA

Schrodere11a represents one genus not previously reported as an effective member of the phytoplankton population of Monterey Bay. The genus made an initial appearance on February 15 at a11 three stations and all depths surveyed except the 15 meter level of Station 2. Figure $15 \mathrm{~b}$ indicates the genus did not appear until one week later at the 15 meter depth at Station 2. The appearance of Schroderella with the initial upwelling occurrence indicates that it requires a relatively high level of nutrient supply. The curve given in Figure 16b indicates the genus occurs in greater numbers at the more seaward Station 3 than at the other two stations. Occurrence throughout the remainder of the research period was intermittent. DINO PHYSIS

A previously unreported dinoflagellate, Dinophysis, was represented intermittently throughout the research period. In Figure 15b, the genus is noted during the first cruise at the. 7.5 meter level at 
Station 2. On February 8, during the initial Upwelling Period at Station 1, the genus represented about $15 \%$ of the total haul. At Station 2 and increase to $8 \%$ was noted at the 7.5 meter level on February 8 and to about the same percent at the 15 meter level during the previous week. Increases in importance occurred earlier at Station 3. During the Davidson Current Period on December 22 at the 7.5 meter level, an increase occurred to over $10 \%$, but at the 15 meter level an increase did not occur until one month later. The pattern of occurrence throughout the period indicates the genus was not influenced by any regime or nutrient parameter.

\section{LITHODESMIUM}

A triangular-shaped centric diatom, Lithodesmium is the last of the previously unreported phytoplankton organisms. Occurring as early as December 16 at Stations 1 and 2 and somewhat later at Station 3 , the genus appeared intermittently through the rest of the research period at both depths. The only time the genus increased markedly was on April 1 at Station 3. At this station the increase was registered at both depths (Figure 16b) but it appears that the upper level had a larger value of $7 \%$ of the total population.

\section{NITZCHIA}

The genus Nitzchla was found on the first cruise at the 7.5 meter level at Station 2 and occurred randomly at other stations, simultaneously at both depths, throughout the remainder of the research period. The only maximum levels of the genus occurred during April at both levels of stations 1 and 2 and at the 7.5 meter level of Station 3 . 
The genus Asterionella is generally considered a high nutrient level organism. The genus occurs generally along with the increases in Chaetoceros. An increased number was found during the last of February and the first of March as the upwelling began. Station 1 gave the largest increase.

$\checkmark$ THALASSIONEMA

The genus occurred randomly and generally was present during an isolated cruise at an isolated sampling point. A simultaneous occurrence at the 15 meter level was noted, however, at Stations 1 and 2 on January 11; but no other simultaneous occurrence was recorded (Figures 14b, 15b, and $16 \mathrm{~b}$ ).

\section{COSCINOSIRA}

The genus Coscinosira cannot be regarded as associated with any particular set of parameters, as indicated by its random occurrence (Figures 14b, 15b, and 16b). Three simultaneous appearances are recorded, however. On February 22 during initial phases of upwelling the genus was noted at the 7.5 meter level at all three stations. On April 1 through April 15 at Station 1 the genus was present at both levels. One week afterward on April 25 Coscinosira was recorded at the 7.5 and 15 meter level of Stations 2 and 3 . 
CONCLUSIONS

OCEANIC PERIODS

(1) The oceanic Period extended through November with moderate salinity values of $33.5^{\circ} \%$ and high temperatures of $14.3^{\circ} \mathrm{C}$.

(2) The Davidson Current Period occurred from late November to early February, and showed a minimum temperature of $10.7^{\circ} \mathrm{C}$ and a maximum salinity of $33.5 \%$ at Station 1 . Another minimum temperature of $11.2^{\circ} \mathrm{C}$ and maximum salinity of $33.54^{\circ} \%$ occurred two weeks later on January 18. Warming due to mixing and inflow occurred after the Initial minimum and continued until the Upweling Period.

(3) The Upwelling Perlod began on February 8 (see Figure 7b). The temperature and salinity curves were altered from those expected by unusually large amounts of precipitation beginning on March 10 . The plotted curves of temperature and salinity indicate the expected drop and rise, respectively, during the initial portion of the period, but commencing with March 10, the temperature values increased and the salinity values decreased and both curves became erratic in Apri1. The exratic curves were the result of precipitation effects exceeding those of upwelling or vice versa. The very low salinity value of Station 1 (Figure 2) on March 25 was not unreasonable when one considers the landward position of the station and high temperature values indicating excessive precipitation and run-off during the interval.

It can be concluded generally that station 1 appeared to respond more rapidly to climatic changes than did the other two stations. This is reasonable because of the relative shallow depth and near-shore position of the Station 1. Station 2 appears 
to have reacted to the changes brought about by current structure more rapidly than the other two stations. It reacted to the climatic changes in the same degree as did Station 1 . Station 3 reacted to changes more slowly and to a lesser degree than did the other two stations. The curves expected during upwelling for temperature and salinity were altered by excessive precipitation within the 15 meter layer studied.

NUTRIENTS

(1) The nutrient curves for the Oceanic Period are at a minimum for the semiannual period at all stations.

(2) The Davidson Current Period is accompanied by a slight increase in nutrient levels during the initial weeks and decreases until the Upwelling Period of early February.

(3) The Upwelling Period is initiated in early February but is slow to reach strength. Indications of strong upwelling are first seen on March 10 at 15 meters at Station 3.

(4) Indications of the upwelling are masked in February and March due to the phytoplankton blooms that occur in the weekly upwelled water.

(5) Variability of nutrient curves during April are due to phytoplankton blooms.

(6) A seaward movement of a high concentration silicate body of water is suggested by data at 7.5 and 15 meters from January 4 to February 1. PHYTOPLANKTON

(1) Five phytoplanktonic genera, Chaetoceros, Rhizosolenia, Peridinium, Ceratium, and Skeletonema, occur at times during the 
sample period with magnitudes of dominance greater than $50 \%$ of the total population.

(2) The genus Chaetoceros is dominant more often than any other and is always associated with nutrient increases.

(3) The genus Rhizosolenia occurs as a dominant form during periods of low nutrient concentration and is the second most common form.

(4) Mixed water forms that require relatively high nutrient levels appeared first on January 4.

(5) The larger and heavier forms of phytoplankton appeared at lower (15 meter) levels in greater numbers.

(6) Phytoplankton blooms do not necessarily originate at Station 3, but were recorded first at the more shoreward Station 1 , especially during the Davidson Current Period.

(7) The greatest bloom occurred at Station 1, and greater numbers of genera were also recorded at Station 1. 
Bolin, R. L. and Abbott, D. P. 1963. Studies on the marine climate and phytoplankton of the central coastal area of California, 1954-1960. California Cooperative Oceanic Fisheries Invest1gations, Reports, Volume IX.

Cupp, Easter E. 1943. Marine Plankton Diatoms of the West Coast of North America, University of California Press.

Edmondson, W. T. 1966. Marine Biology III, Proceedings of the Third International Interdiciplinary Conference, New York Academy of Science.

Hardy, Sir Alister C. 1965. The Open Sea; The World of Plankton, Col11ns.

Newe11, G. E. and Newe11, R. C. 1963. Marine Plankton, A Practical Guide, Hutchinson Educational.

$\checkmark$ Raymount, John E. G. 1963. Plankton and Productivity in the Oceans, MacMillian Company.

Strickland, J. D. H. and Parsons, T. R. 1965. A manual of sea water analysis. Fisheries Research Board of Canada, Bulletin 非125.

Sverdrup, Johnson, and Flemming. 1942. The Oceans, Their Physics, Chemistry, and General Biology, Prentice Hall.

Wickstead, John H. 1965. An Introduction to the Study of Tropical Plankton, Hutchinson Tropical Monographs.

Winpenny, R. S. 1966. The Plankton of the Sea, American Elsevier Publishing Company. 
Defense Documentation Center

Cameron Station

Alexandria, Virginia 22314

Library

Naval Postgraduate School

Monterey, California 93940

Department of Meteorology and Oceanography

Naval Postgraduate School

Monterey, California 93940

Dr. E. C. Haderlie

Department of Meteorology and Oceanography

Naval Postgraduate School

Monterey, California 93940

Director, Naval Research Laboratory

Attn: Tech. Services Info. Officer

Wasbington, D. C. 20390

Oceanographer of the Navy

The Madison Bullding

$732 \mathrm{~N}$. Washington Street

Alexandria, Virginia 22314

Naval Oceanographic Office

Attn: Library

Washington, D. C. 20390

Office of Naval Research

Attn: Blology Branch Code 446

Department of the Navy

Washington, D. C. 20360

LT Robert Horton Welch, USN

217 West I Street

Elizabethton, Tennessee 37643 


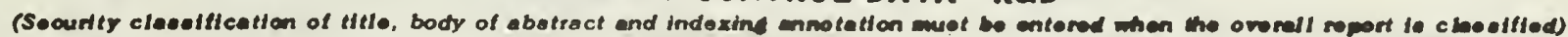
1. ORIGINATIN G ACTIVITY (Corporate outhor) Naval Postgraduate School Monterey, California 93940 Unclassified 2b. onoue

3. REPONT TITLE

A STUDY OF THE STRATIFICATION OF PHYTOPLANKTON AT SELECTED LOCATIONS IN MONTEREY BAY, CALIFORNIA

4. DESCRIPTIVE NOTES (Type of report and Inchulve Lateo)

Final 9 November 1966 thru 25 Apr11 1967

5. AUTHOR(S) (Leat name. Hret neas, InIttal)

WELCH; Robert H.

Lieutenant, USN

\begin{tabular}{|c|c|}
\hline $\begin{array}{l}\text { 6. AEPOAT DATE } \\
26 \text { May } 1967\end{array}$ & \begin{tabular}{|c|c|} 
76. TOTAL NO. OF PACES & 7b. NO. OF REFE \\
68 & 10 \\
\end{tabular} \\
\hline $\begin{array}{l}\text { - a. CONTRACT OR ORANT NO. } \\
\text { b. PROJECT NO. }\end{array}$ & 9. ORIGINATOR'S REPORT NUMBEA(S) \\
\hline o. & 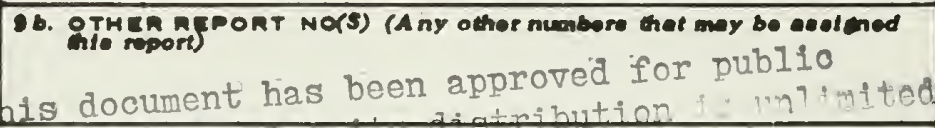 \\
\hline 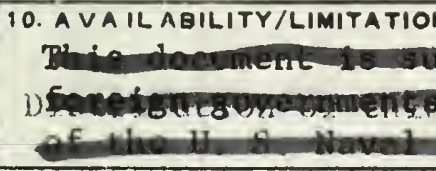 & 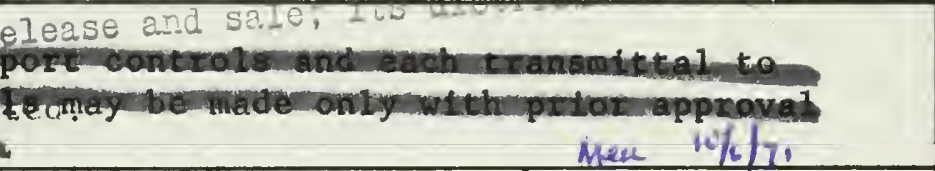 \\
\hline 11. SUPPL EMENTARY NOTES & $\begin{array}{l}\text { 12. SPONSORING MILITARY ACTIVITY } \\
\text { Navy Oceanographic Office }\end{array}$ \\
\hline
\end{tabular}

13. ABSTRACT

Relationships between genera of phytoplankton present and the parameters of oceanographic regime and nutrient supply have been given. The research was made at three selected off-shore stations in Monterey Bay, California. Sampling and analysis procedures are described. Results of nutrient analysis include reactive phosphate and silicate. A temperature and salinity profile is described for each station. Phytoplankton analysis lists five genera of dinoflagellates and sixteen genera of diatoms. The research extends for a six month period beginning in November, 1966, and concludes in April, 1967. 


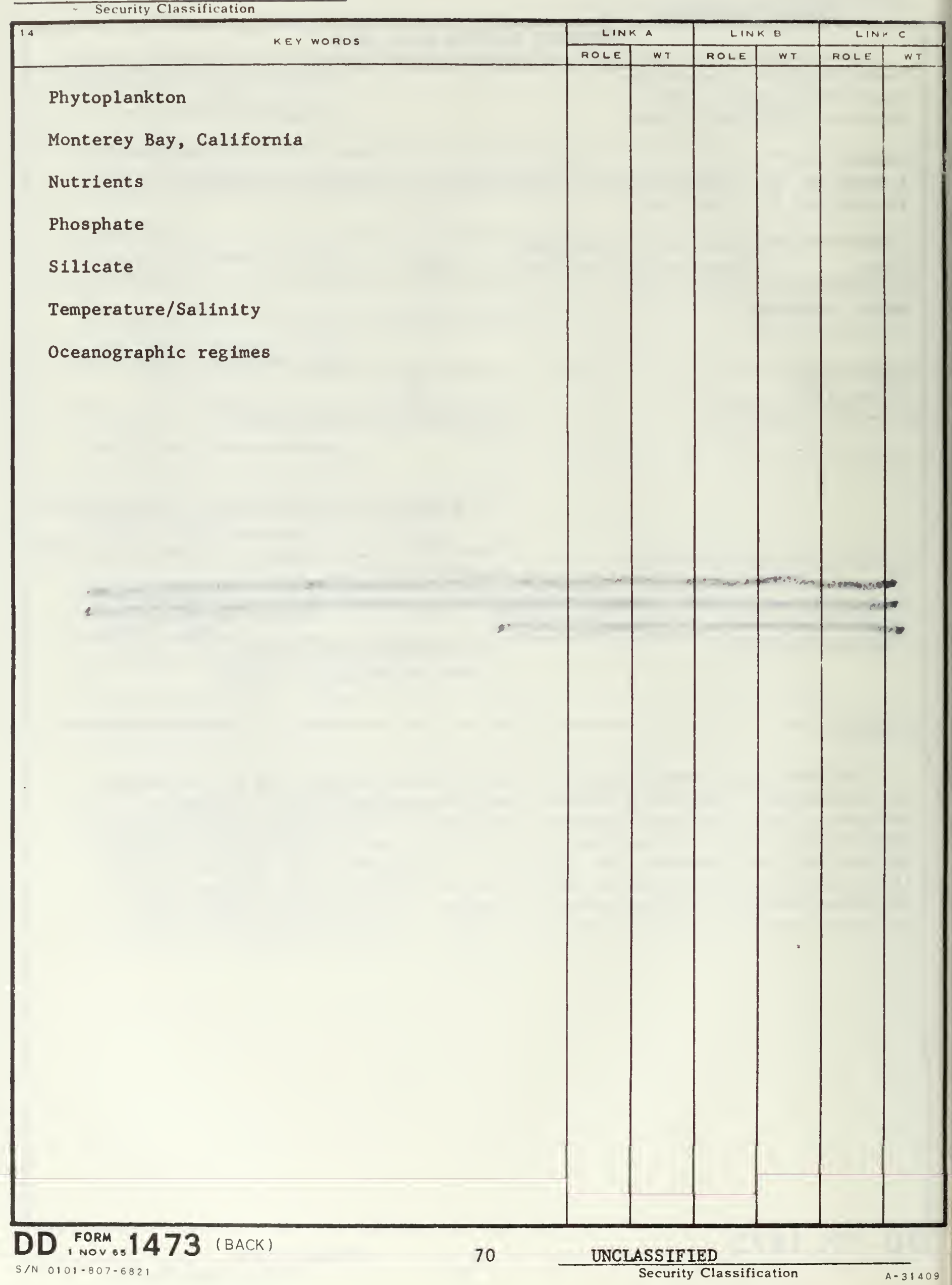








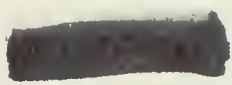




\section{thesW394}

A study of the stratification of phytopl

.

in:

32768001952088

DUDLEY KNOX LIBRARY 